\title{
ipen
}

AUTARQUIA ASSOCIADA A UNIVERSIDADE DE SÃO PAULO

\section{ESTUDO DA MAGNETITA COMO MATERIAL ADSORVEDOR DE ÍONS URANILO}

\section{ROBERTO LEAL}

Dissertação apresentada como parte dos requisitos para obtenção do Grau de Mestre em Ciências na Área de Tecnologia Nuclear - Materiais.

Orientadora:

Dra. Mitiko Yamaura 


\section{Instituto de Pesquisas Energéticas e Nucleares $10 \mathrm{C}$}

"Autarquia associada à Universidade de São Paulo"

ESTUDO DA MAGNETITA COMO MATERIAL ADSORVEDOR DE ÍONS URANILO

Roberto Leal

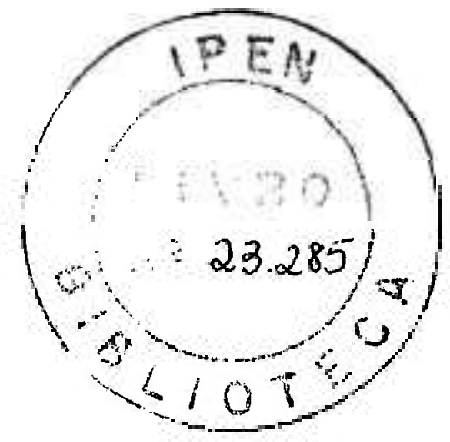

Dissertação apresentada como parte dos requisitos para obtenção do Grau de Mestre em Ciências na Área de Tecnologia Nuclear - Materiais.

Orientadora:

Dra. Mitiko Yamaura

SÃO PAULO

2006 


\section{Instituto de Pesquisas Energéticas e Nucleares ip}

"Autarquia associada à Universidade de São Paulo"

\section{ESTUDO DA MAGNETITA COMO MATERIAL ADSORVEDOR DE ÍONS URANILO \\ (REVISADO PELO AUTOR)}

Roberto Leal

Dissertação apresentada como parte dos requisitos para obtenção do Grau de Mestre em Ciências na Área de Tecnologia Nuclear - Materiais.

Orientadora:

Dra. Mitiko Yamaura

SĀO PAULO

2006 
A Príscila Leal, pela compreensão, amor, incentivo e apoio em todos os momentos.

À minha riqueza e filha Anna Giulia Leal. 


\section{AGRADECIMENTOS}

\section{A DEUS.}

À Dra. Mitiko Yamaura pelo apoio, paciência e profissionalismo com que orientou os estudos teóricos e práticos. Pela amizade, compree: säo nos momentos difíceis e de dúvidas, fazendo com que o presente trabalho se desenvolvesse de forma coerente.

À Dra. Maria Aparecida Faustino Pires gerente do Centro de Química e Meio Ambiente (CQMA-IPEN) pela análise do trabalho e dicas preciosas durante a fase de elaboração da dissertação.

Ao Dr. Paulo Ernesto O. Lainetti e ao Instituto de Pesquisas Energéticas e Nucleares - IPEN, pela oportunidade e estrutura fornecida junto ao Centro de Quimica e Meio Ambiente para a realização dos experimentos e desenvolvimento da pesquisa.

Aos pesquisadores e técnicos envolvidos na etapa de caracterização.

Aos colegas da Divisão que direta ou indiretamente colaboraram para a realização deste trabalho, em especial a Maria José Alves de Oliveira pela indicação do programa.

Ao Biólogo Luiz Cláudio Barbosa Stopa pela amizade, pelo incentivo e pelas valiosas trocas de idéias durante a realização dos estudos.

Aos meus pais, Marcolino e Gema, pela sólida educação, pelos exemplos de vida e apoio em quaisquer circunstâncias, estendendo também aos meus irmãos Mauro, Márcio, Marco e Márcia

À vovó Lourdes, ao vovô Mário e a bisa Anna pela força na educação da minha filha nos momentos ausentes. 


\section{SUMÁRIO}

Página

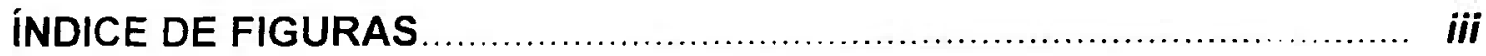

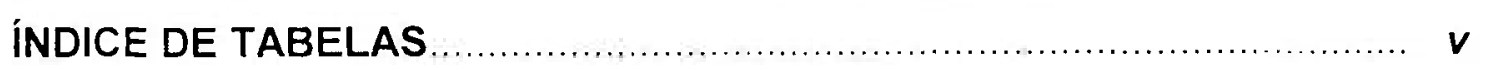

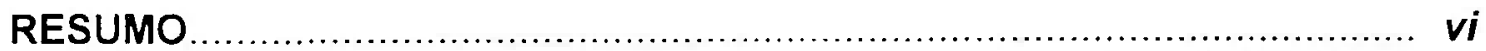

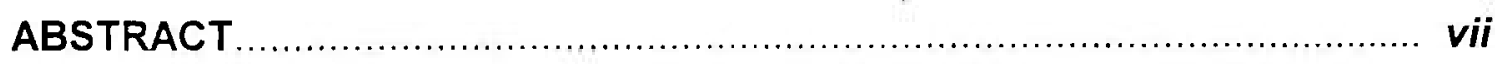

1. INTRODUÇÃO

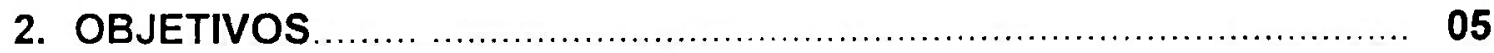

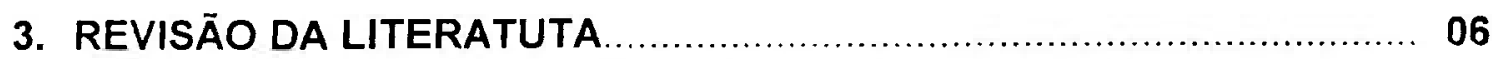

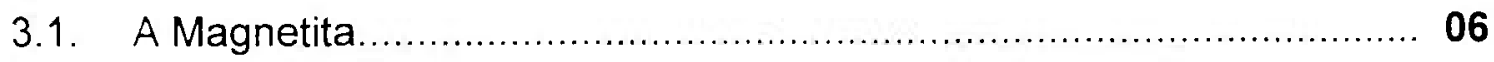

3.1.1. Ocorrência e Obtenção.............................................................. 06

3.1.2. Estrutura e Propriedades Gerais................................................... 07

3.1.3. Aplicações Ambientais e Biomédicas ............................................... 08

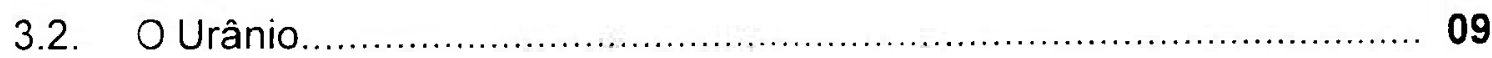

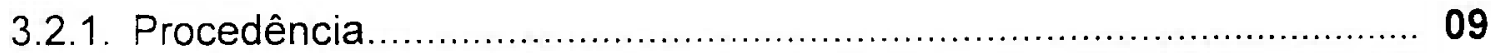

3.2.2. Rejeitos Radioativos de Urânio.................................................... 10

3.2.3. Rejeitos Radioativos de Urânio de Outras Fontes............................ 12

3.3. Separação Magnética................................................................ 13

3.4. Separação por Adsorção ........................................................... 14

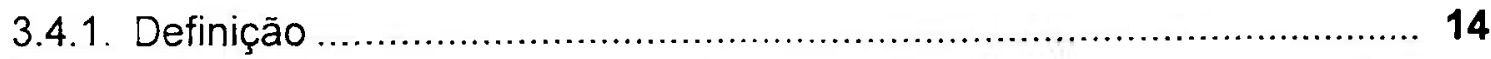

3.4.2. Mecanismos de Adsorção de Íons Uranilo pela Magnetita................. 16

3.4.3. Porcentagem de Remoção ........................................................ 18

3.4.4. Isotermas de Adsorção............................................................... 18

3.4.5. Energia Livre de Gibbs............................................................ 20

3.5. Técnicas de Caracterização........................................................... 21

3.5.1. Difração de Raios-X ............................................................... 21

3.5.2. Curvas de Magnetização........................................................ 23

3.5.3. Análise por Microscopia Eletrônica de Varredura (MEV) .................. 25 
3.6. Método Analítico.

3.6.1. Espectrofotometria de Absorção

4. MATERIAIS E MÉTODOS

4.1. Equipamentos e Materiais de Laboratório

4.2. Preparação de Nanoparticulas de Magnetita Superparamagnétice: por Precipitação Simultânea

4.3. Preparação de Soluções de Urânio.

4.3.1. Preparação de Soluções de Urânio em Diferentes $\mathrm{pH}$ a partir de Solução Padrão.

4.3.2. Preparação de Soluções de Urânio com Concentrações Diferentes a partir de Solução Padrão

4.4. Processo de Adsorção

4.5. Análise de $\mathrm{UO}_{2}{ }^{2+}$ em Arsenazo III por Espectrofotometria

5. RESULTADOS E DISCUSSÃO

5.1. Caracterização das Nanopartículas de Magnetita. 36

5.1.1. Difração de Raios-X. 36

5.1.2. Medidas Magnéticas 37

5.1.3. Microscopia Eletrônica de Varredura. 39

5.2. Estudo de Adsorção.

5.3. Cinética de Adsorção.

5.4. Isotermas de Adsorção

5.4.1. Isotermas de Adsorção de İons de $\mathrm{UO}_{2}{ }^{2+}$. de Soluções Nítricas para a Magnetita Lavada com Metanol.

5.4.2. Isotermas de Adsorção de lons de $\mathrm{UO}_{2}{ }^{2+}$. de Soluções Nitricas para a Magnetita Lavada com Água

5.5. Energia Livre de Gibbs 


\section{INDICE DE FIGURAS}

FIGURA 1 - Cristal de Magnetita.

FIGURA 2 - Ciclo do Combustivel Nuclear.

FIGURA 3 - Formação de Principais Espécies de Urânio em Solução Aquosa com o Aumento do $\mathrm{pH}$

FIGURA 4 - Difração de Raios-X em uma Estrutura Cristalina.

FIGURA 5 - Curva de Histerese.

FIGURA 6 - Seqüência de Preparação das Nanoparticulas de Magnetita.

FIGURA 7 - Partículas de Magnetita Obtidas por Processo de Precipitação Simultânea.

FIGURA 8 - Particulas de Magnetita sob Ação de um Campo Magnético de um Imã.

FIGURA 9 - Procedimento Experimental para Estudos de Adsorção.

FIGURA 10 - Relação entre Absorbância e o Comprimento de Onda (nm) do Complexo $\mathrm{UO}_{2}{ }^{2+}$ - Arsenazo III......

FIGURA 11 - Curva de Calibração para $\mathrm{O}_{\mathrm{UO}_{2}}{ }^{2+} \mathrm{em}$ Arsenazo III 0,06\%, $\lambda=650 \mathrm{~nm}$ (balão $=5 \mathrm{~mL}$ )

FIGURA 12 - Difratograma das Nanopartículas de Magnetita. Radiação Incidente de CuKa.

FIGURA 13 - Difratograma da Magnetita. Base de dados JCPDS - JCDD19629

FIGURA 14 - Nanoparticulas de Magnetita Atraidas por um Imã.

FIGURA 15 - Curva de Magnetização das Nanopartículas de Magnetita. 
FIGURA 16 - Micrografia das Nanopartículas de Magnetita por MEV.

FIGURA 17 - Variação da \% de Remoção de $\mathrm{UO}_{2}{ }^{2+}$ pela Magnetita em Função da Variação do $\mathrm{pH}$.

FIGURA 18 - Variação da Capacidade de Adsorção da Magnetita em Função da Dose para $\mathrm{UO}_{2}{ }^{2+}$ em Soluções Nitricas. $27^{\circ} \mathrm{C} \ldots \ldots .$.

FIGURA 19 - Variação da \% de Remoção da Magnetita em Função da Dose para $\mathrm{UO}_{2}{ }^{2+}$ em Soluções Nítricas, $27^{\circ} \mathrm{C}$.

FIGURA 20 - Variação da \% de Remoção de $\mathrm{UO}_{2}{ }^{2+}$ de Soluções Nitricas, em Função do Tempo de Agitação.

FIGURA 21 - Variação da \% de Remoção de $\mathrm{UO}_{2}{ }^{2+}$. de Soluções Nítricas de $\mathrm{pH}=5$ : em Função da Freqüência de Agitação..

FIGURA 22 - Isoterma Linearizada de Langmuir para $\mathrm{UO}_{2}{ }^{2+}$ de Soluções Nítricas em pH 5 para a Magnetita Lavada com Metanol, $27^{\circ} \mathrm{C}$.

FIGURA 23 - Isoterma Linearizada de Freundlich para $\mathrm{UO}_{2}{ }^{2+}$ de Soluções Nítricas em $\mathrm{pH} 5$ para a Magnetita Lavada com Metanol, $27^{\circ} \mathrm{C}$.

FIGURA 24 - Isotermas de Adsorção de Langmuir e Freundlich para $\mathrm{UO}_{2}{ }^{2+}$ de Soluções Nitricas em $\mathrm{pH} 5$ para a Magnetita Lavada com Metanol. $27^{\circ} \mathrm{C}$

FIGURA 25 - Isoterma Linearizada de Langmuir para $\mathrm{UO}_{2}{ }^{2+}$ de Soluções Nitricas em pH 5 para a Magnetita Lavada com Água, $27^{\circ} \mathrm{C}$.....

FIGURA 26 - Isoterma Linearizada de Freundlich para $\mathrm{UO}_{2}{ }^{2+}$ de Soluções Nitricas em pH 5 para a Magnetita Lavada com Água, $27^{\circ} \mathrm{C}$......

FIGURA 27 - Isotermas de Adsorção de Langmuir e Freundlich para $\mathrm{UO}_{2}{ }^{2+}$ de Soluçōes Nitricas para a Magnetita Lavada com Água, em $\mathrm{pH} 5,27^{\circ} \mathrm{C}$ 


\section{INDICE DE TABELAS}

TABELA 1 - Tipos de Adsorção Conforme a Variação da Energia Livre de Gibbs (\lrcorner $G^{\circ}$ ads $)$

TABELA 2 - Parâmetros de Langmuir e Freundlich para Adsorção de lons de Urânio de Meio Nitrico, $p H 5$, dose $15 \mathrm{~g} \cdot \mathrm{L}^{-1}$, a $27^{\circ} \mathrm{C}$, para a Magnetita (com Metanol)

TABELA 3 - Parâmetros de Langmuir e Freundlich para Adsorção de lons de Urânio de Meio Nitrico, $p H 5$, dose 15 g. $L^{-1}$, a $27^{\circ} \mathrm{C}$, para a Magnetita (com Água). 


\title{
ESTUDO DA MAGNETITA COMO MATERIAL ADSORVEDOR DE IOONS URANILO
}

\author{
Roberto Leal
}

\section{RESUMO}

\begin{abstract}
A magnetita, também chamada de ferrita de ferro, é um minério conhecido como imã natural e encontrada em depósitos de ferro. Além desse comportamento intrinseco, a magnetita possui a capacidade de remover os ions metálicos do meio aquoso por fenômenos de adsorção. O seu caráter fortemente magnético a distingue de outros tipos de adsorventes, visto que, é facilmente removida da solução por separação magnética. Neste trabalho estudou-se a adsorção de urânio(VI), na forma de íns $\mathrm{UO}_{2}{ }^{2+}$, de solução nitrica pela magnetita sintética. Esta foi preparada por precipitação simultânea adicionando-se uma solução de $\mathrm{NaOH}$ à solução contendo os ions $\mathrm{Fe}^{2+}$ e $\mathrm{Fe}^{3+}$. A magnetita sintética, na forma de um pó preto, exibiu uma resposta magnética de atração intensa na presença de um campo magnético, sem contudo tornar-se magnética, um comportamento típico de material superparamagnético constatado por medidas de magnetização. Estudou-se a influência dos parâmetros de adsorção de ions $\mathrm{UO}_{2}{ }^{2+}$ tais como o pH, a dose do adsorvente, tempo de contato e a isoterma de equilíbrio. A máxima adsorção de urânio foi encontrada no intervalo de pH entre 4 e 5. Verificou-se que quanto maior a dose de magnetita menor a capacidade de adsorção e maior a remoção de $U$. Da relação entre adsorção e tempo de contato verificou-se que a remoção aumentou rapidamente com o tempo e atingiu-se a condição de equilibrio em $30 \mathrm{~min}$. Os resultados da isoterma de equilíbrio apresentaram maior concordância com o modelo de Langmuir, o qual permitiu a determinação da capacidade teórica de saturação da magnetita para 0 urânio. A interação entre os ions $\mathrm{UO}_{2}{ }^{2+}$ e a magnetita foi caracterizada como uma adsorção quimica e espontânea.
\end{abstract}




\title{
STUDY OF MAGNETITE AS ADSORBENT MATERIAL OF URANYL IONS
}

\author{
Roberto Leal
}

\section{ABSTRACT}

Magnetite, also known as iron ferrite, is a mineral iron and a natural magnet found in iron deposits. In addition to its magnetic intrinsic behavior, the magnetite has the capacity to remove the metallic ions from aqueous medium by adsorption phenomena. The strong magnetic character of magnetite distinguishes it from other adsorbent types, which it allows to be readily removed from solution by magnetic separation. In this work, uranium ( $\mathrm{VI}$ ) adsorption, as $\mathrm{UO}_{2}{ }^{2+}$ ions, from nitric solution by synthetic magnetite was investigated. It was prepared by simultaneous precipitation process, adding a $\mathrm{NaOH}$ solution into a solution containing $\mathrm{Fe}^{2+}$ and $\mathrm{Fe}^{3+}$ ions. The synthetic magnetite, a black powder, has exhibited a strong magnetic response in presence of a magnetic field, without nevertheless becomes magnetic. This typical superparamagnetic behavior was confirmed by magnetization measurements. Adsorption parameters of $\mathrm{UO}_{2}{ }^{2+}$ ions such as $\mathrm{pH}$. the adsorbent dose, contact time and equilibrium isotherm were evaluated. Maximum uranium adsorption was observed in the $\mathrm{pH} \mathrm{4.0-5.0} \mathrm{range.} \mathrm{It}$ was noticed that increase in magnetite dose increased the percent removal of uranium, but decreased the adsorption capacity of the magnetite. It was observed from the relation between adsorption and contact time that the removal has increased very fast with time, and achieved the equilibrium within 30 minutes. The results of equilibrium isotherm agreed well with the Langmuir model, and so the theorical saturation capacity of the magnetite was determined for uranyl ions. The interaction between $\mathrm{UO}_{2}{ }^{2+}$ ions and the magnetite was defined as a spontaneous chemical adsorption. 


\section{INTRODUÇÃO}

O uso de materiais provenientes de descartes de processos industriais e de utilizações domésticas tem sido muito estudado para a busca de alternativas e soluções para a preservação do meio ambiente. Muitas empresas têm se preocupado com a questão ambiental, principalmente no que tange a adequaçāo aos limites determinados pela legislação associada à melhoria de métodos e processos para uma produção "limpa", atendendo as exigências mercadológicas.

Quando se trata de melhorar processos, um dos fatores importantes a ser considerado é com relação aos resíduos desta produção. É cada vez mais necessário buscar soluções que minimizem os problemas de geração de resíduos, que a principio seriam simplesmente descartados causando muitas vezes impacto ambiental.

Muito investimento vem sendo feito no intuito de pesquisadores de empresas, institutos de pesquisas, universidades, desenvolvam métodos e técnicas eficazes no controle de emissão de poluentes, com custos reduzidos e com ênfase no reaproveitamento de materiais.

Uma das grandes preocupações mundiais em relação ao meio ambiente tem sido com a escassez de recursos naturais, tendo como conseqüência uma constante conscientização com o uso adequado e controlado desses recursos. Dentro deste contexto temos o exemplo da água que apesar de representar a maior parte do globo. pouco se tem para uso potável.

A preocupação com os recursos hídricos existentes faz parte dos muitos estudos abordados na atualidade, pois não tem como desvincular 0 crescimento industrial e populacional, da necessidade de uso dos mesmos. 
Além de ter o recurso, é necessário preservá-lo e evitar que se contamine de forma acelerada, como vem acontecendo das últimas décadas para cá, principalmente em função do crescimento populacional, tecnológico e produtivo.

Em função de uma não conscientização por parte da população e um controle ineficiente da legislação ambiental, muitos residuos industriais e domésticos são lançados em corpos d'água. Como o volume vem aumentando com o tempo, principalmente em áreas industriais e com grande densidade populacional, está cada vez mais evidente que só com implantação de métodos alternativos, educação ambiental e políticas eficientes, pode-se ter a certeza de uma melhor qualidade de vida futura.

Em se tratando de efluentes industriais e domésticos, muitos metais tóxicos tem sido lançados, comprometendo a qualidade das águas. Muitos métodos convencionais empregados no tratamento desses efluentes são de difícil aplicação e apresentam custos elevados. A aplicação de métodos alternativos com baixo custo se faz necessário, como questão muitas vezes de sobrevivência para pequenas e médias empresas, que precisem se adequar às exigências e legislações vigentes.

A técnica de adsorção tem sido uma das alternativas a ser investigada utilizando adsorventes orgânicos como os residuos agro-industriais, o bagaço de cana-de-açúcar e a casca de arroz [1-4].

Entre os diversos adsorventes inorgânicos de baixo custo, existem os compostos de ferro que apresentam estrutura quimica favorável a adsorção de ions metálicos [5.6]. Um adsorvedor inorgânico muito empregado e que faz parte desse estudo é a magnetita $\left(\mathrm{Fe}_{3} \mathrm{O}_{4}\right)$, que pode ser obtida como resíduo de processos siderúrgicos ou por precipitação simultânea a partir de sais de ferro, conseguindo assim uma forma de reduzir custos na aquisição e proporcionar 0 uso por empresas de pequeno porte em seus sistemas de controle de emissão de poluentes ao meio ambiente. 
Dentre os mais variados efluentes industriais com necessidade de tratamento, estão os efluentes nucleares que em sua composição contém muitos metais tóxicos e radioativos, como o urânio [7].

Em se tratando dos grandes volumes de rejeito nuclear provenientes do ciclo do combustivel e o seu gerenciamento, a descontaminação a níveis aceitáveis para descarte. sem causar danos à saúde da população e ao meio ambiente, requer tratamentos complexos e dispendiosos em função da radioatividade e, principalmente, da alta toxicidade. Duas tecnologias tradicionais utilizadas na separação de elementos radioativos nas etapas de processamento do combustivel nuclear ou de tratamento das soluções de rejeitos são troca iônica e extração por solventes. Entretanto, considerando a complexidade da composição química e a radioatividade das soluçōes a serem tratadas, em alguns casos os custos excessivos com equipamentos e associada às baixas concentrações dos radionuclídeos, tornam ambas tecnologias em processos de tratamento muitas vezes ineficientes. Além disso, elas geram quantidades significantes de rejeitos secundários indesejáveis e suas aplicações são limitadas em função das restrições técnicas, do processo e econômicas

Dentro desse cenário desponta-se a tecnologia combinando a técnica de separação magnética com a técnica de separação química como, por exemplo, por adsorção como uma alternativa para substituir as tecnologias tradicionais. A aplicação de separação magnética tem se destacado devido à simplicidade de operação, baixo custo e sem geração, ou mínima, de efluentes secundários quando comparada com extração por solvente e troca iônica e, a técnica de separação por adsorção é altamente efetiva para descontaminação de baixas concentraçōes de contaminantes. A tecnologia de separação magnética e química em rejeitos radioativos torna-se possivel somente com 0 uso de materiais adsorvedores magnéticos.

Neste trabalho. estudou-se a magnetita sintética preparada no laboratório e verificou-se a sua propriedade magnética, bem como o processo de adsorção para ions $\mathrm{U}^{6+}$ na forma de ions $\mathrm{UO}_{2}{ }^{2+}$, em meio nitrico. 
A relevância e a finalidade prática deste estudo foi obter parâmetros para uma utilização eficiente desse adsorvente na tecnologia de separação magnética e química para $\circ$ tratamento de rejeitos líquidos radioativos, proveniente do ciclo do combustivel nuclear, tornando-os rejeitos radioativos sólidos compactos, de volume menor e conseqüente redução do espaço de armazenamento. 


\section{OBJETIVOS}

O principal objetivo desse trabalho foi avaliar a propriedade magnética e a eficiência de adsorção das partículas de magnetita $\left(\mathrm{Fe}_{3} \mathrm{O}_{4}\right)$ sintética para os ions $\mathrm{UO}_{2}{ }^{2+}$. A magnetita foi obtida por precipitação simultânea de uma solução aquosa contendo os ions $\mathrm{Fe}^{2+}, \mathrm{Fe}^{3+} \mathrm{e} \mathrm{OH}^{-}$. Os estudos consistiram de: caracterização da magnetita sintética, determinação da eficiência de remoção de ions $\mathrm{UO}_{2}{ }^{2+}$, influência do $\mathrm{pH}$, dose de magnetita, velocidade de adsorção, tempo de equilibrio, energia livre de Gibbs e isotermas de adsorção. 


\section{REVISÃO DA LITERATURA}

\subsection{A Magnetita}

\subsubsection{Ocorrência e Obtenção}

A magnetita ou ferrita de ferro, $\mathrm{FeO} . \mathrm{Fe}_{2} \mathrm{O}_{3}$, é um óxido formado por ions de ferro de valências diferentes. É um minério de ferro conhecido como imã natural encontrado em depósitos de ferro e um dos mais usados para a obtenção de ferro e aço.

É encontrada disseminada nas rochas igneas e metamórficas, em certos tipos de bactérias como, por exemplo, na Aquaspirillum magnetotacticum [8], em grande quantidade nas areias de praia conhecidas como areia mineral, areia ferrosa ou areia preta.

No Brasil, a região do Quadrilátero Ferrifero, Minas Gerais. possui importantes depósitos ricos em minerais de ferro, principalmente hematita ( $\alpha$ $\mathrm{Fe}_{2} \mathrm{O}_{3}$ ) e magnetita, intercaladas com segmentos em quartzo e/ou dolomita [9].

A magnetita por apresentar uma estrutura cristalina simples pode ser facilmente preparada em laboratório por neutralização de uma solução aquosa contendo ions férricos e ferrosos com uma solução alcalina de $\mathrm{NaOH}$ [10]. 


\subsubsection{Estrutura e Propriedades Gerais}

A magnetita possui estrutura magnética, tendo as resultantes dos momentos magnéticos não nulas, o que a torna de caráter ferromagnética. Porém aquecendo-a acima de $580^{\circ} \mathrm{C}$ ocorre um magnetismo desordenado, passando a um estado paramagnético.

Apresenta estrutura cristalina do tipo espinélio, fortemente magnético, semelhante a montmorilonita, $\mathrm{Al}_{4} \mathrm{Si}_{8} \mathrm{O}_{20}(\mathrm{OH})_{4} \mathrm{nH}_{2} \mathrm{O}$, com ions $\mathrm{O}^{2-}$ de empacotamento cúbico, os ions maiores $\mathrm{Fe}^{2+}$ nos interstícios octaédricos, a metade dos ions $\mathrm{Fe}^{3+}$ em sítios octaédricos e metade restante em posições tetraédricas, semelhante a de muitos minerais [11-15].

É um composto com uma estrutura cristalina favorável a utilização como material adsorvedor, pois em solução aquosa possui espaços entre as camadas hidratadas e planos com cargas superficiais que tendem a atrair e fixar certos eiementos carregados tanto positivamente como negativamente [16].

Com base na estrutura apresentada e considerando a importância da magnetita como um material magnético, é importante salientar que se trata de um material com grande aplicação como adsorvente em processos de tratamento de efluentes contaminados.

A magnetita possui em sua composição química $31,0 \%$ de $\mathrm{FeO}$ e $69,0 \%$ de $\mathrm{Fe}_{2} \mathrm{O}_{3}$ e cristalografia isométrica de classe hexaoctaédrica.

Sua densidade é de $5,2 \mathrm{~g} \cdot \mathrm{mL}^{-1}$, dureza 5,5 a 6 e seu ponto de fusão é de $1597^{\circ} \mathrm{C}$. 
É um composto solúvel em ácidos e insolúvel em água. É encontrada sob a forma de cubos ou em pó e tem como cor o preto metálico e brilho lustroso, conforme mostra a FIG. 1.

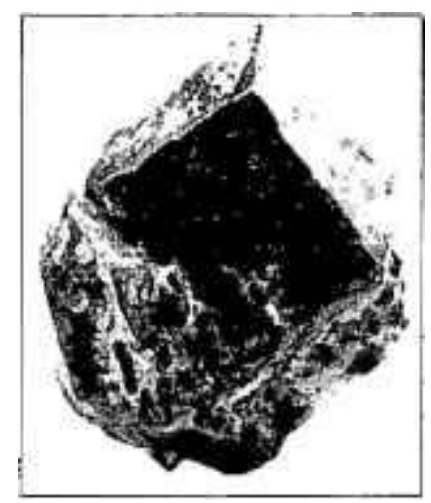

FIGURA 1 - Cristal de Magnetita [17].

\subsubsection{Aplicações Ambientais e Biomédicas}

A magnetita pode ser aplicada na remoção de íns metálicos, compostos orgânicos, material particulado e material biológico do meio aquoso por adsorção (processo "ex-situ") ou durante a formação da molécula na etapa de precipitação (processo "in-situ"), em processos de descontaminação de água e na remoção de actinídeos do rejeito líquido proveniente da indústria nuclear $[15,16$, $18,19,20,21,22]$.

É possivel usá-la recoberta com material orgânico, tornando-se um composto adsorvedor alternativo e eficiente, além de ser usado na área médica. Um exemplo disso. é o uso de nanopartículas de magnetita, recobertas com quitosana, em forma de esferas ou cápsulas [23]. Esses complexos podem ser aplicados a processos de tratamento de efluentes na remoção de ions metálicos e no tratamento terapêutico de células com câncer por hipertermia localizada, em conjunto com radio e quimioterapia, além do uso como agente de contraste em imagem de exame de ressonância magnética [24]. 


\subsection{O Urânio}

\subsubsection{Procedência}

O urânio é um elemento natural de símbolo $U$ e de massa atômica igual a 92 (92 prótons e 92 elétrons) em estado sólido à temperatura ambiente. Dentre os elementos encontrados na natureza é o de maior número atômico e os elementos que o seguem na tabela periódica são todos artificiais. É um metal radioativo, denso, dúctil e maleável, mal condutor de eletricidade.

O urânio reage praticamente com todos os elementos não-metálicos, exceto gases nobres; dissolve-se em ácido cloridrico e nítrico, enquanto que os ácidos não oxidantes como o sulfúrico, fosfórico e similares. dissolvem-no muito lentamente. É inerte aos álcalis, mas não aos peróxidos, com os quais forma peruranatos [25].

O urânio é encontrado na natureza na forma de três isótopos: ${ }^{238} \mathrm{U}$ com $99,28 \%,{ }^{235} \cup$ com $0,71 \%$ e ${ }^{234} \cup$ com $0,006 \%$. O urânio-235 sofre fissão nuclear com nêutrons lentos e é utilizado como combustivel em reatores nucleares e em função de sua reduzida quantidade é necessário obtê-lo pelo processo de enriquecimento de átomos ou isótopos de urânio-238 de forma a aumentar a porcentagem do urânio-235. Esse processo é realizado nas usinas de enriquecimento, por meio de ultracentrifugas [26].

É encontrado em abundância (2,4 ppm na crosta terrestre), fazendo parte da constituição de muitos óxidos minerais originários de rochas sedimentares como granitos. basaltos, com uma dureza um pouco menor que a do aço, de cor branco-niquel. pertencente na classificação periódica à classe dos actinideos.

Um dos minérios mais importantes de urânio é a uraninita, uma mistura de $\mathrm{UO}_{2}$ e $\mathrm{U}_{3} \mathrm{O}_{8}$. que contém pequenas quantidades de rádio, tório, polônio, 
chumbo e hélio. Quando a uraninita ocorre de forma massiva, com um certo brilho, é chamada pechblenda. considerado o principal minério de urânio.

Outros minerais que contêm urânio são a euxenita. a carnotita, a branerita e a cofinita. Os principais depósitos destes minérios situam-se nos EUA, Canadá, Rússia e França [27. 28].

Para a obtenção de urânio, o minério é extraido do solo por procedimentos de mineração e submetido aos processos de beneficiamento. $\mathrm{Na}$ usina de beneficiamento, o urânio é extraido do minério, purificado e concentrado.

O concentrado obtido é um sal de cor amarela chamado diuranato de amônio, mais conhecido como "yellowcake", matéria prima para a produção da energia gerada em um reator nuclear.

O Brasil ocupa a sexta posição no ranking mundial de reservas de urânio (aproximadamente 309.000 te $\mathrm{U}_{3} \mathrm{O}_{8}$ ). Sendo que apenas $25 \%$ do território nacional foi objeto de prospecção, e as duas principais delas são a de Caetité (mina Lagoa Real - BA), e Santa Quitéria (Ceará).

A mina de Caetité localizada a $20 \mathrm{~km}$ da sede do municipio, produz "yellowcake". Esta reserva possui um teor médio de 3.000 ppm (partes por milhão), capaz de suprir dez reatores do porte de Angra 2 durante toda sua vida útil.

O urânio extraído tem como aplicações principais o uso em geração de energia como fonte de combustivel, material radioativo para uso na medicina e na agricultura [29].

\subsubsection{Rejeitos Radioativos de Urânio}

Todo processo industrial resulta em rejeitos ou residuos, que deverão ter seus destinos tratados como um dos fatores mais importantes de todas as 
etapas de produção. No caso do ciclo do combustivel nuclear, representado pela FIG. 2. tem-se uma geração de rejeitos em praticamente todos os estágios. desde a mineração até 0 reprocessamento. Em todas as etapas são gerados basicamente rejeitos de urânio e seus derivados.

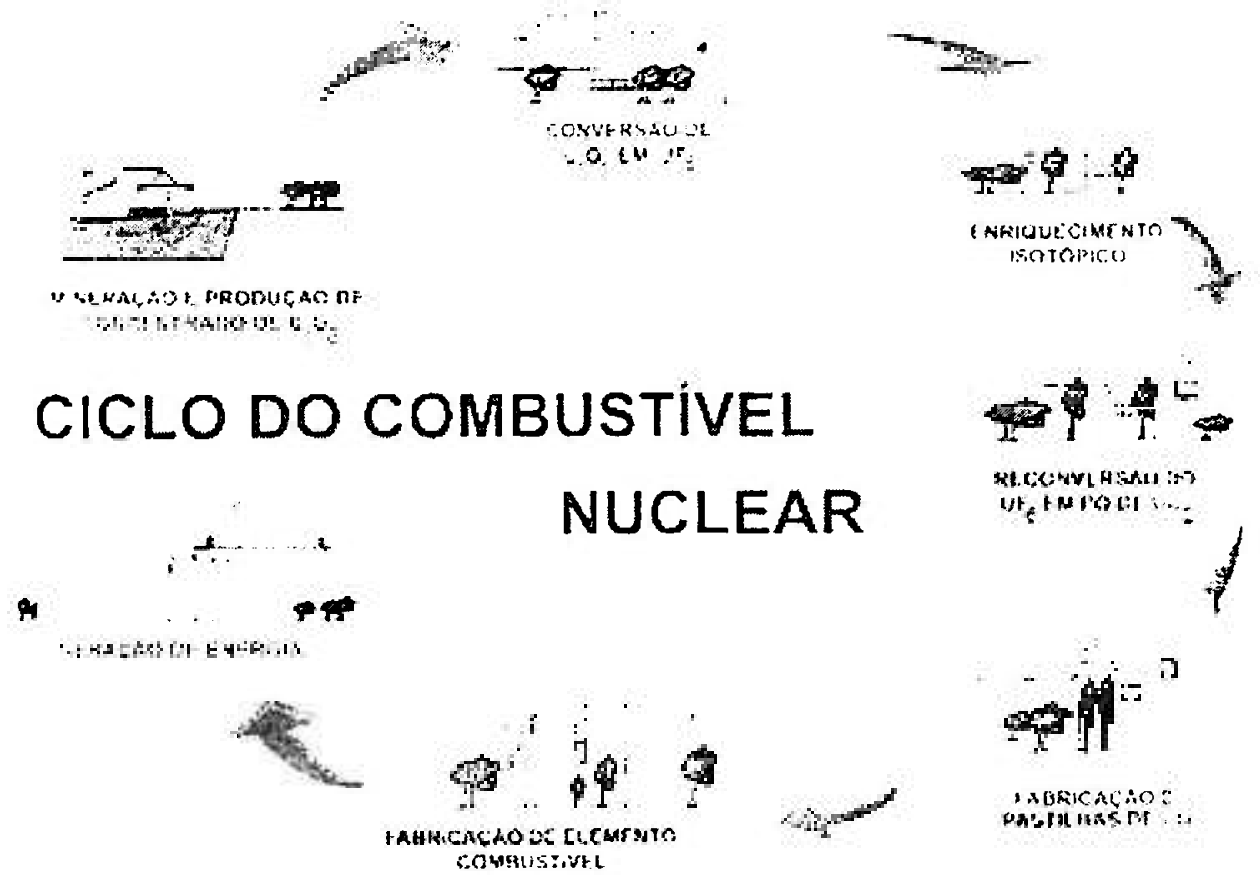

Fonte: INB

FIGURA 2 - Ciclo do Combustivel Nuclear.

Muitas atividades humanas que envolvem materiais radioativos também geram rejeitos radioativos como em hospitais, clínicas, universidades e centros de pesquisas.

Isótopos radioativos são gerados na operação de reatores nucleares, tais como: plutônio, césio, iodo. criptônio e estrôncio. Além destes. existem residuos líquidos, sólidos e gasosos que são gerados e lançados diretamente no meio ambiente, com os devidos controles para que a radioatividade natural esteja aentro dos limites aceitáveis [30].

Todos estes rejeitos são classificados segundo a sua radioatividade [31] em : 
- rejeito de baixa atividade: contém baixo teor de radionuclideos e portanto não requer blindagem durante o manuseio e transporte:

- rejeito de média atividade: contém alto teor de radionuclídeos e requer blindagem com pouco ou nenhum dissipador de calor durante o manuseio e transporte;

- rejeito de alta atividade: rejeito altamente radioativo que gera quantidade significante de calor durante o processo de decaimento radioativo.

Os elementos combustiveis, com os produtos de fissão e o que restou de urânio. constituem os rejeitos de atividade alta. O maior volume de rejeitos gerados estão concentrados na mineração e beneficiamento do minério de urânio e são considerados rejeitos de atividade média e baixa e são armazenados no próprio local.

Grande quantidade de lixo radioativo de atividade média e baixa também é produzida quando um reator nuclear é desativado. Isso porque muitas das peças que o compõem, incluindo o combustivel, tornam-se radioativas. 0 processo de tratamento de uma usina nuclear nesse ponto é chamado "descomissionamento" [32].

\subsubsection{Rejeitos Radioativos de Urânio de Outras Fontes}

As conseqüências da exposição a radiações provocadas pelos processos e fontes radioativas contidas nos rejeitos, não estão somente ligadas aos processos de geração de energia nuclear e atividades humanas que usam materiais radioativos. Existem, por exemplo, fontes de radiação associadas à produção de fertilizantes fosfatados, que possuem urânio, na forma de $\mathrm{U}_{3} \mathrm{O}_{3}$. presente na fração argilosa e no fosfogesso obtidos durante o beneficiamento do minério. o qual geram um volume de urânio muito maior que o processo para geração de energia elétrica [33]. 
Outros exemplos podem ser citados como a queima do carvão mineral em siderurgias, que contém elementos radioativos como urânio e tório, nas partículas presentes nas cinzas e fumaça. Um dos maiores problemas é que, tanto o fosfogesso quanto às cinzas do carvão podem ser utilizadas na construção civil e na agricultura, aumentando consideravelmente a exposição ao meio ambiente [34].

\subsection{Separação Magnética}

Todos os materiais apresentam algum grau de propriedades magnéticas e podem ser classificados em três categorias quanto à susceptibilidade magnética [35]:

1. Materiais diamagnéticos - apresentam valores negativos de susceptibilidade magnética. tais como a água e a maioria dos compostos orgânicos e gases.

2. Materiais paramagnéticos - apresentam baixos valores positivos de susceptibilidade magnética tais como os compostos constituídos de elementos de transição.

3. Materiais ferromagnéticos e ferrimagnéticos - que apresentam altos valores de susceptibilidade magnética como os compostos de ferro, cobalto, niquel e elementos de terras raras.

A separação magnética foi introduzida como um processo de controle da poluição para muitos problemas ambientais e industriais [22,36], incluindo o tratamento de efluente proveniente da fábrica de aço, usina de carvão, separação e concentraçāo de minérios.

Os materiais magnéticos, como a magnetita natural [15] ou sintética [37] são bons adsorventes e apresentam grande potencial de aplicação na remoção de levedura de meio aquoso, purificação da água de fonte, tratamento de água doméstico e de água subterrânea. A magnetita tem sido estudada para separar os actinideos ( $\mathrm{Pu}$ ) do rejeito nuclear [38] bem como reter metais tóxicos de águas contaminadas [39]. Esta caracteristica adsortiva juntamente com o seu 
caráter fortemente magnético faz com que a magnetita possa ser aplicada nos processos de descontaminação da água e na remoção de metais de efluentes aquosos, combinando as técnicas de adsorção e a separação magnética.

A separação magnética é um processo físico que separa um constituinte de uma mistura com base na susceptibilidade magnética dos materiais. A separação magnética utilizando um gradiente de campo magnético (High Gradient Magnetic Separation - HGMS) separa particulas ferromagnéticas e paramagnéticas de materiais diamagnéticos. As particulas com uma susceptibilidade positiva (ferro e paramagnéticas) são atraídas em direção ao aumento do gradiente magnético e podem ser extraidas de um meio contendo partículas com susceptibilidade negativa (diamagnéticas). A tecnologia usa somente propriedades físicas e portanto produz um mínimo de efluente secundário $[40,41]$.

\subsection{Separação por Adsorção}

\subsubsection{Definição}

Existem muitos processos de separação propostos [42-49] para a remoção de urânio das águas residuais industriais e rejeitos radioativos, sendo os mais usados a troca iônica, a precipitação quimica, a extração por solvente e a adsorção. Dentre estes, o processo de adsorção é o mais efetivo para soluções diluídas.

O método de separação por adsorção tem sido muito empregado para purificação de substâncias ou para separação das mesmas. Em escala comercial o processo de adsorção é dividido em duas técnicas, quanto ao modo operacional: processos cíclicos em batelada ou processos contínuos em contracorrente [50].

No estudo da literatura verificam-se muitas contribuições para o aprimoramento do processo de adsorção de íons uranilo, com a finalidade de 
explicar o fenômeno e buscar alternativas efetivas e de baixo custo com adsorventes como o carvão ativado [51], casca de coco [52], montmorilonita [53], biomassas [54,55], minerais [56], fosfatos [57], microorganismos, entre outros.

Os estudos de adsorção datam da Segunda metade do século XVIII na Suécia, quando foi observada a adsorção de gases por carbono ativado, tendo mais tarde um uso muito importante na confecção de máscaras para proteção durante a primeira guerra mundial.

Adsorção é o termo usado para descrever o fenômeno no qual moléculas de um fluido se concentram sobre uma superfície sólida, quando em contato por um tempo a uma dada temperatura. As moléculas presentes na fase fluida são atraidas para a zona interfacial devido à existência de forças atrativas não compensadas na superfície do sólido.

O fenômeno de adsorção é constituido por uma fase sólida (adsorvente) que em contato com uma solução contendo um soluto (adsorbato), provoca um aumento ou diminuição do soluto na interface. A adsorção pode ser classificada em 2 tipos: física não localizada e quimica localizada [58].

A física não localizada ou simplesmente adsorção física, ocorre por forças de interação molecular envolvendo dipolos permanentes e os dipolos induzidos, pela atração superficial que envolve o fenômeno de condensação ou atração por força de Van der Waals. É denominada não localizada pelo fato das moléculas adsorvidas poderem se movimentar livremente sobre a superfície adsorvedora, em interaçōes fisicas.

Já na química localizada ou simplesmente adsorção química, ocorre por formação de ligaçōes químicas entre valências livres do sólido e do adsorbato, onde há um rearranjo de forças, estando restrito a primeira camada superficial do adsorvente e é denominada localizada pelo fato das moléculas adsorvidas estarem localizadas em posições especificas na superficie do sólido. 


\subsubsection{Mecanismos de Adsorção de Íons Uranilo pela Magnetita}

Ao longo dos últimos 20 anos, muitos trabalhos de interação de radionuclideos, em particular o urânio, com a superfície de oxi-hidróxidos de $\mathrm{Fe}^{3+}$ tem sido intensivamente realizados $[59,60]$ para uma maior compreensão sobre a migração de radionuclídeos nas corrosões observadas nos tambores em que são armazenados a fim de diminuir o impacto radiológico no meio ambiente. Por outro lado, estudos de adsorção em óxidos contendo $\mathrm{Fe}^{2+}$, como a magnetita, são limitados consideravelmente.

Os trabalhos expressivos encontrados na literatura relacionados à adsorção de ions uranilo pela magnetita citam-se, por exemplo. os efeitos de carbonato na recuperação de $U^{5+}$ pela magnetita considerando $0 \mathrm{pH}$, a força iônica [61] e as isotermas de adsorção utilizando uma magnetita com baixa relação de $\mathrm{Fe}^{2+} / \mathrm{Fe}^{3+}(0,08)$ e em condições anaeróbicas [62]. Existem ainda os estudos realizados sobre os efeitos de ânions na adsorção de uranilo na magnetita em concentrações fixas de uranilo e força iônica [63] e de Missana e colaboradores [64] que analisaram a adsorção nas condições livres de $\mathrm{CO}_{2}$ e $\mathrm{O}_{2} \mathrm{e}$ interpretaram o mecanismo usando um modelo de complexação de superfície.

Nesse estudo, Missana considerou o modelo de adsorção de dupla camada difusa [65], onde a interface óxido/água é descrita como duas camadas de carga. A primeira localizada na superficie do óxido e formada especificamente por adsorção de ions do líquido, e a segunda uma camada difusa de ions de carga oposta, balanceando a carga superficial, formada muito próxima à superfície do sólido.

Supondo um só sítio de adsorção, para assegurar a simplicidade, o modelo de dupla camada difusa foi aplicado considerando somente um tipo de sitio de adsorção $\mathrm{SOH}$, onde $\mathrm{S}$ é o sólido e $\mathrm{OH}$ o grupo hidroxila. e dois tipos de adsorbato: o primeiro envolvendo dois diferentes complexos monodentados, e o segundo, um complexo bidentado binuclear simples.

Da curva de evolução de espécies de urânio mostrada na FIG. 3, Missana e colaboradores verificaram que as espécies dominantes em $\mathrm{pH}$ menor 
que 5, a região onde ocorre a maioria dos processos de adsorção. são $\cup_{2}{ }^{2+} \mathrm{e}$ $\mathrm{UO}_{2} \mathrm{OH}^{+}$. Em pH entre 5.5 e 8.5, $\mathrm{UO}_{2}(\mathrm{OH})_{2}{ }^{0}$ torna-se a espécie dissolvida predominante, enquanto $\mathrm{em} \mathrm{pH}$ maiores a espécie predominante é a de carga negativa, $\mathrm{UO}_{2}(\mathrm{OH})_{3}$ :

Portanto, como uma primeira tentativa de modelar, as duas espécies predominantes consideradas foram $\mathrm{UO}_{2}^{+}, \mathrm{UO}_{2} \mathrm{OH}^{+}$, os quais foram supostos reagir com o sitio ativo da superficie do óxido. A adsorção de ions uranilo na superficie dos grupos funcionais $\mathrm{SOH}$ foi descrita com reações do tipo (1) e (2), para o complexo do tipo monodentado:

$$
\begin{gathered}
\mathrm{SOH}+\mathrm{UO}_{2}{ }^{2+} \leftrightarrow \mathrm{SOUO}_{2}{ }^{+}+\mathrm{H}^{+} \\
\mathrm{SOH}+\mathrm{UO}_{2} \mathrm{OH}^{+} \leftrightarrow \mathrm{SOUO}_{2} \mathrm{OH}+\mathrm{H}^{+}
\end{gathered}
$$

e (3) para ligação do tipo bidentado binuclear:

$$
2 \mathrm{SOH}+\mathrm{UO}_{2}{ }^{2+} \leftrightarrow(\mathrm{SO})_{2} \mathrm{UO}_{2}+2 \mathrm{H}^{+}
$$

Um ajuste satisfatório para as duas aproximações foi obtido em comportamento do tipo Langmuir.

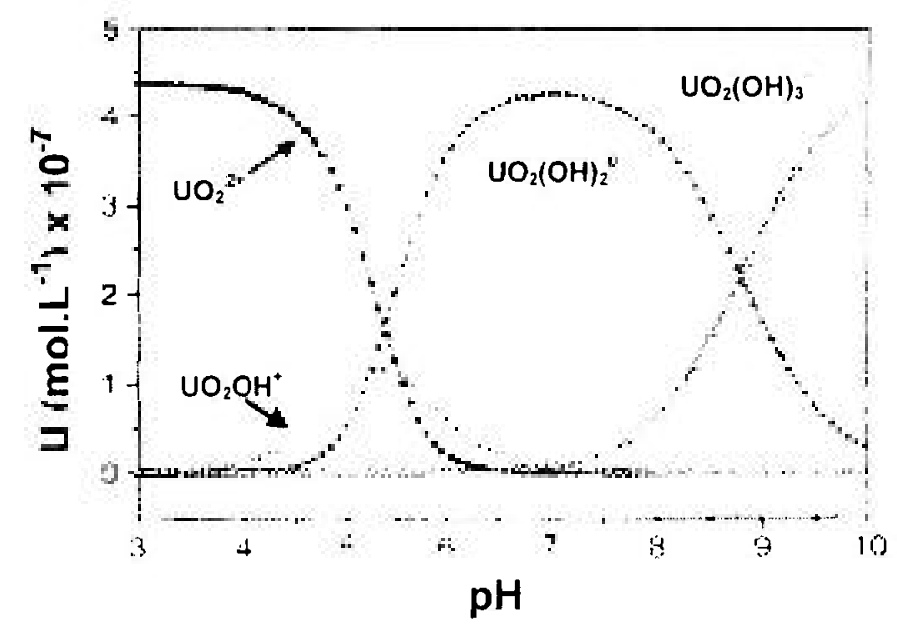

FIGURA 3 - Formação de Principais Espécies de Urânio em Solução Aquosa com

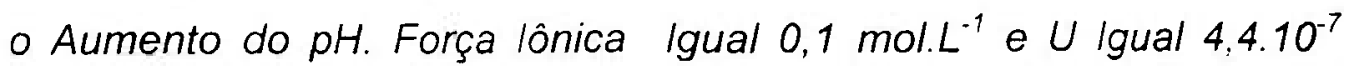
mol. $L^{-1}[64]$. 


\subsubsection{Porcentagem de Remoção}

Uma grandeza que descreve a quantidade de soluto adsorvido pelo adsorvente é a porcentagem de remoção do soluto, demonstrada na equação (4):

\% Remoção $=\left(C_{0}-C\right) \cdot 100 / C_{0}$

Em que: $C_{o}$ e $C$ são as concentrações iniciais e finais da espécie adsorvida, respectivamente.

\subsubsection{Isotermas de Adsorção}

De um modo geral, a relação de equilibrio entre a quantidade de um metal adsorvido e a sua concentração remanescente na solução é descrita e quantificada por meio de uma isoterma que permite conhecer a natureza dos processos de adsorção.

A isoterma de adsorção geralmente é expressa em gráfico de concentração de metal adsorvido $q_{\mathrm{eq}}\left(\mathrm{mg} \mathrm{g}^{-1}\right)$ versus a concentração na solução $\mathrm{C}_{\mathrm{eq}}\left(\mathrm{mg} \cdot \mathrm{L}^{-1}\right)$, em equilibrio à temperatura constante [66].

Os dois modelos de isotermas de adsorção mais utilizados são: Isoterma de Langmuir e Isoterma de Freundlich.

\section{Isoterma de Langmuir}

A teoria de Langmuir considera o fenômeno de adsorção em superficie homogênea com um número fixo de posições de adsorção disponiveis na superficie, com a formação de uma camada monomolecular, e que as moléculas adsorvidas não sofrem interação com o meio e nem entre si $[66,67]$. 
A equação de Langmuir foi definida baseada em adsorção localizada e química em superfície homogênea com ausência de forças de atração entre as moléculas adsorvidas e a monocamada, considerando-se a adsorção de um único adsorbato e que um sítio na superficie do adsorvente pode ser ocupado apenas por uma molécula de adsorbato.

O modelo descreve a seguinte equação:

$$
q_{e q}=Q K_{L} \cdot C_{e q} /\left(1+K_{L} \cdot C_{e q}\right)
$$

onde $K_{L}$ é a constante de Langmuir relacionado com a energia de adsorção e $Q$ é a capacidade máxima de adsorção. A equação (5) pode ser arranjada de forma linear:

$$
C_{\mathrm{eq}} / \mathrm{q}_{\mathrm{eq}}=1 / \mathrm{q}_{\mathrm{eq}} K_{L}+C_{\mathrm{eq}} / Q
$$

As constantes $Q$ e $K_{L}$ podem ser determinadas pela inclinação e 0 coeficiente linear da equação linear.

\section{Isoterma de Freundlich}

Esse modelo foi um dos pioneiros em equacionar a relação entre a quantidade de material adsorvido e a concentração do material na solução. $O$ modelo propõe que o número de sitios de adsorção é muito maior que o número de moléculas de soluto, e assim, estas são "infinitamente" acumuladas na superficie, sem atingir a saturação do adsorvente. O modelo considera a não uniformidade da superficie e interações com as moléculas adsorvidas. O processo de adsorção apresenta uma distribuição exponencial de calores de adsorção a partir da monocamada adsorvida e propõe a seguinte equação:

$$
q_{e q}=K_{F} \cdot C_{e q}{ }^{k n n}
$$


A sua forma linearizada é descrita pela equação (8):

$$
\log q_{e q}=\log K_{F}+1 / n \log C_{e q}
$$

Onde $K_{F}$ e $1 / n$ são as constantes de Freundlich e são indicadores da capacidade de adsorção e intensidade de adsorção, respectivamente. O vaior de $1 / n$ menor do que uma unidade indica uma adsorção favorável e se $n$ for igual a 1 , a isoterma se torna linear [66].

\subsubsection{Energia Livre de Gibbs}

O estudo termodinâmico da adsorção pelo cálculo da energia livre de Gibbs, mostra se está ocorrendo adsorção física ou quimica, ou seja, indica o tipo de interação que ocorre entre a superficie do adsorvente e a espécie adsorvida, conforme TAB. 1.

A partir dos valores das constantes de Langmuir $K_{L}$ extraidos das isotermas [68] é possivel calcular a energia de adsorção $\Delta G^{\circ}{ }_{\text {ads, também }}$ conhecida como energia livre de Gibbs, segundo a equação (9):

$$
\Delta \mathrm{G}_{\mathrm{ids}}^{0}=-R T \ln K_{\mathrm{L}}
$$

Onde:

$R=$ constante universal dos gases $\left(8,314 \mathrm{~J} \cdot \mathrm{K}^{-3} \cdot \mathrm{mol}^{-1}\right)$

$T=$ temperatura em Kelvin

Quando a energia livre de Gibbs é negativa, o processo de adsorção é espontâneo. O tipo de adsorção é determinado conforme valores em módulo de \lrcorner $G_{\text {ads, }}^{\circ}$ conforme TAB. 1 [16]. 
TABELA 1 - Tipos de Adsorção Conforme a Variação da Energia Livre de Gibbs $\left(\Delta \mathrm{G}^{\circ}\right.$ ads $)[16]$.

\begin{tabular}{ll}
\hline$\Delta \mathrm{G}^{\circ}{ }_{\text {ads }}\left(\mathrm{kJ.mol}{ }^{-1}\right)$ & Tipo de adsorção \\
\hline 1 a 5 & Física \\
5 a 20 & Ativada \\
$>20$ & Química \\
\hline
\end{tabular}

\subsection{Técnicas de Caracterização}

\subsubsection{Difração de Raios-X}

Os raios-X são caracterizados pelas radiações eletromagnéticas de mesma natureza que a luz visivel, porém com comprimento de onda menor. $O$ espectro de luz visivel apresenta comprimento de onda na faixa de 400 até 700 $\mathrm{nm}$. No caso do estudo de difração, trabalha-se com comprimento de onda na faixa de 0,5 a $2,5 \AA$ e dentro do espectro eletromagnético estão entre os raios gama e ultravioleta.

A geração ocorre quando se submete um elemento a um feixe de elétrons. O elemento alvo possui um arranjo atômico formado por bilhões de átomos, em uma estrutura definida de linhas agrupadas, variando-se de acordo com a sua eletrosfera que juntas vão produzir o espectro característico. Filtros são usados para separar comprimentos de onda de maior e menor intensidade.

É muito importante e determinante, no estudo da difração de raios- $X$, observar a estrutura cristalina que o elemento alvo possui pois, o espectro será formado de acordo com este arranjo que é constituído por cristais com inúmeras e menores unidades estruturais dentro de um mesmo arranjo atômico. Essas unidades estão distribuidas ordenadamente e se repetem tridimensionalmente formando reticulados cristalinos. 
Uma rede cristalina apresenta planos com diferentes espaçamentos. A distância interplanar $\mathbf{d}_{\mathbf{h k l}}$ é função dos índices de Miller (hkl) e das constantes cristalográficas $[69,70]$.

A determinação da estrutura cristalina do elemento alvo ocorre pelo espaçamento interplanar, intensidades relativas geradas entre as reflexões e a comparação com dados do JCPDS - ICDD (Joint Committee on Powder Diffraction Standards - International Centre of Diffraction Data). Uma difração com a posição e intensidade de picos bem definidos permitem determinar a estrutura cristalina e identificar os componentes [71].

A FIG. 4 mostra uma estrutura cristalina, onde os átomos funcionam como obstáculos, ou centros de espalhamento dos raios-X.

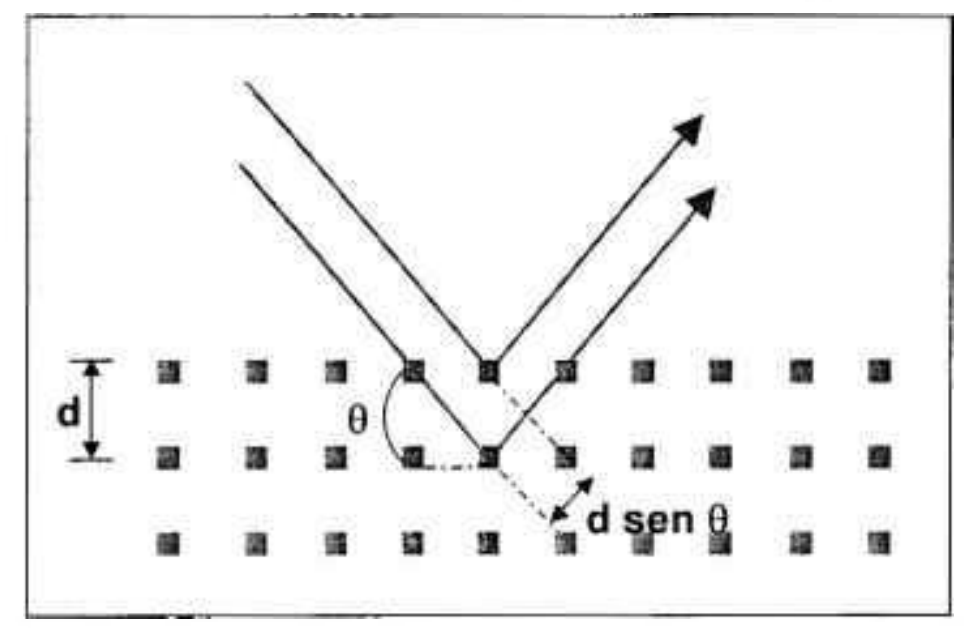

FIGURA 4 - Difração de Raios-X em uma Estrutura Cristalina.

Com a incidência interplanar de um feixe de raios- $X$, com distância $\mathrm{d}$ e ângulo de incidência $\theta$ os feixes refletidos por dois planos subseqüentes apresentarão o fenômeno da difração.

Se a diferença entre seus caminhos óticos for um número inteiro de comprimentos de onda, haverá superposição construtiva (um feixe de raios- $X$ será observado).

A expressão que representa o fenômeno, que também é conhecida como lei de Bragg, é mostrada na equação (10): 


$$
2 d \operatorname{sen} \theta=n \lambda
$$

Em que: d é a distância interplanar, $\lambda$ é o comprimento de onda da radiação utilizada, $\mathbf{n}$ representa as várias ordens de reflexão e $\theta$ é ângulo de incidência.

\subsubsection{Curvas de Magnetização}

O comportamento dos materiais magnéticos pode ser estudado por representações gráficas em que são medidas a indução magnética ou magnetização em função do campo magnetizante ou desmagnetizante [35].

Quando a magnetização atinge um máximo e se torna constante, ocorre a magnetização de saturação. Nesse momento, o aumento da força de magnetização não exerce mais nenhuma influência no material. As curvas traçadas entre o inicio do processo até atingir a saturação são denominadas curvas de magnetização.

Com a determinação das curvas é possivel analisar as propriedades magnéticas dos materiais, tais como: retentividade, que consiste na habilidade que o material possui de reter parte do magnetismo após a interrupção da força magnetizante. relutância, que é a propriedade de dificultar a aplicação de um campo magnético (materiais muito permeáveis são pouco relutantes), coercividade, que é uma magnetização inversa que tem a função de anular o magnetismo residual e magnetismo remanente, que se trata do magnetismo retido após a desmagnetização.

O comportamento magnético mostrado pelas curvas de magnetização muda de acordo com o material em função de cada um possuir permeabilidades diferentes. 
Materiais com baixa permeabilidade, de difícil magnetização, apresentam uma curva de histerese mais larga, mostrando que se trata de um material com altas retentividade, relutância, força coerciva e alto magnetismo residual.

Por outro lado, materiais com alta permeabilidade, de fácil magnetização. apresentam uma curva de histerese mais estreita, mostrando-se um material com baixas retentividade, relutância, força coerciva e baixo magnetismo residual.

A FIG.5 mostra o modelo da curva de magnetização e desmagnetização, conhecida também como curva de histerese. Observa-se a aplicação de um campo magnético de intensidade $H$ em função da magnetização do material com densidade de fluxo $B$ até atingir o ponto de saturação $a$. Com a retirada da força imantadora, nota-se a retentividade em $\boldsymbol{b}$ e a coercividade em $\boldsymbol{c}$, que aparecerá com a inversão do campo magnético e aumento da força imantadora no sentido oposto até atingir novamente a saturação em $\boldsymbol{d}$.

Elevando-se a força imantadora no sentido original completa-se o segmento $d$ e $f a$, e repetindo-se o processo têm-se os ciclos de histerese.

No caso de materiais ferro ou ferrimagnéticos em escala nanométrica, da ordem de algumas dezenas de nanômetros, observa-se que os mesmos deixam de atuar como magnetos permanentes e passam a apresentar propriedades superparamagnéticas, caracterizadas por elevada magnetização de saturação e ausência de magnetização residual, depois de cessada a aplicação do campo magnético. Neste caso verifica-se a não ocorrência da histerese. É possível controlar o movimento das partículas com a aplicação de um campo magnético, possibilitando a separação e o isolamento do meio com facilidade com o auxílio de um imã [72]. 


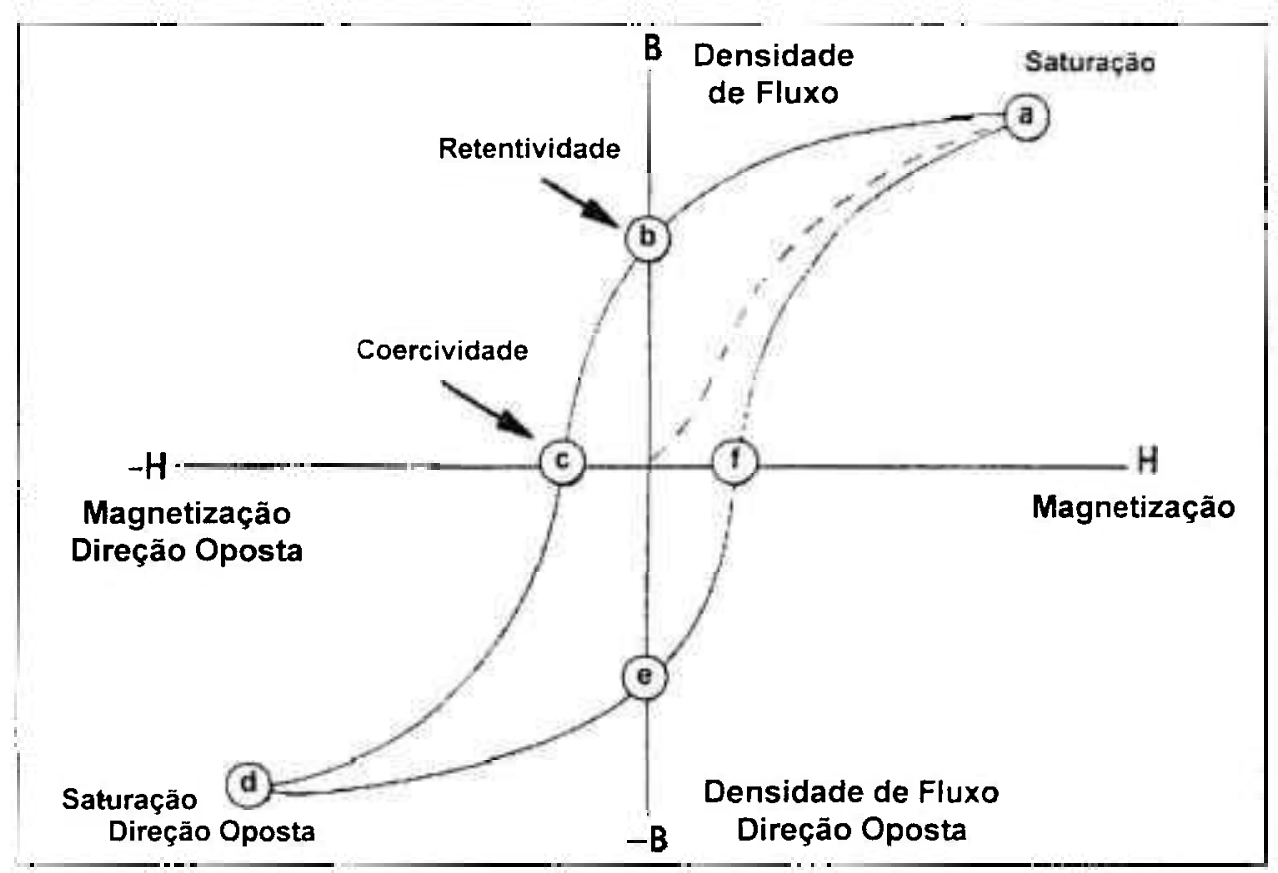

FIGURA 5 - Curva de Histerese.

\subsubsection{Análise por Microscopia Eletrônica de Varredura (MEV)}

Dentro da caracterização dos materiais existe a análise morfológica, que deve ser feita com o auxílio de um microscópio eletrônico de varredura, MEV (Scanning Electron Microscope, SEM), pelo qual se obtêm informações estruturais e químicas.

A microscopia eletrônica de varredura é uma técnica muito importante e vem sendo usada com muita freqüência, pois é possivel obter informações detalhadas, com aumentos de imagem em até 300.000 vezes dependendo do material, mas para caracterização de materiais normalmente o aumento é da ordem de 10.000 vezes

O processo consiste em bombardear a amostra, sob vácuo, com um feixe fino de elétrons de alta energia que incide na superfície, ocorrendo uma interação. Parte do feixe é refletida e coletada por um detector que converte este sinal em imagem de BSE (ou ERE) - imagem de elétrons retroespalhados - ou 
nesta interação a amostra emite elétrons produzindo a chamada imagem de ES (elétrons secundários).

Ocorre também a emissão de raios- $X$ que fornece a composição química elementar de um ponto ou região da superficie, possibilitando a identificação de praticamente qualquer elemento presente.

A imagem é formada pelo mapeamento e a contagem de elétrons secundários e retroespalhados emitidos pela amostra, que irá fornecer informações sobre a morfologia da amostra.

Ao MEV pode ser acoplado o sistema EDS (Energy Dispersive System), possibilitando a análise da composição qualitativa e semi quantitativa da amostra, utilizando-se raios- $X$ caracteristicos $[73,74]$.

\subsection{Método Analítico}

\subsubsection{Espectrofotometria de Absorção}

A espectrofotometria pode ser conceituada como um procedimento analítico pelo qual se determina a concentração de espécies químicas mediante a absorção de energia radiante (luz). A espectrofotometria baseia-se na absorção da radiação nos comprimentos de onda entre o ultravioleta e o infravermelho. É uma técnica de fácil aplicação e de rápida obtenção dos resultados.

A variação da cor de um sistema, com a modificação de um certo componente é a base da técnica; tal variação ocorre devido a formação de um composto cromóforo resultante da adição de um reagente apropriado e que pode ser comparada com a que se obtém pelo tratamento idêntico de uma quantidade conhecida da substância. Aqui, portanto, determina-se a concentração de uma substância pela medida da absorção relativa de luz, tomando como referência a absorção da substância numa concentração conhecida. Esse método 
proporciona um meio simples para determinar quantidades diminutas de substâncias.

A luz pode ser entendida como uma forma de energia. de natureza ondulatória, caracterizada pelos diversos comprimentos de onda $(\bar{i}$, expressos em $\mathrm{nm}$ ) e que apresenta a propriedade de interagir com a matéria, sendo que parte de sua energia é absorvida por elétrons da eletrosfera dos átomos constituintes das moléculas.

Uma solução quando iluminada por luz branca, apresenta uma cor que é resultante da absorção relativa dos vários comprimentos de onda que a compõem. Esta absorção, em cada comprimento de onda, depende da natureza da substância, de sua concentração e da espessura da mesma que é atravessada pela luz.

A análise espectrofotométrica baseia-se na Lei de Lambert-Beer, ou seja, a absorbância é proporcional à concentração da espécie quimica absorvente, sendo constantes o comprimento de onda, a espessura atravessada pelo feixe luminoso e demais fatores. Verifica-se uma relação linear entre absorbância ou densidade óptica e concentração, e de uma relação logarítmica entre transmitância e concentração [75]. 


\section{MATERIAIS E MÉTODOS}

\subsection{Equipamentos e Materiais de Laboratório.}

- Espectrofotômetro de UV-Vis, mod. B582, Micronal;

- Balança analítica digital, mod. BP210D, Sartorius AG, RFA;

- pHmetros;

- Agitadores modelo AD8850, Donner;

- Peneiras granulométricas de 30 e 80 mesh, Bertel;

- Pipetas automáticas de volume fixo e regulável;

- Solução padrão de Nitrato de Uranilo;

- Arsenazo III;

- Cloreto de ferro II tetrahidratado;

- Cloreto de ferro III hexahidratado;

- Ácido Nítrico;

- Hidróxido de Sódio;

- Ácido ascórbico;

- Microscópio eletrônico de varredura (MEV), LEO 440i, Instituto de Pesquisas Energéticas e Nucleares (IPEN/SP);

- magnetômetro de amostra vibrante, PRINCETON APPLIED, model 530 , Centro Brasileiro de Pesquisas Fisicas (CBPF/RJ);

- difratômetro de raios-x, RIGAKU modelo RINT 2000/PC, com goniômetro de textura e software de controle e aquisição de dados, Universidade Federal de Sergipe (UFS). 


\subsection{Preparação de Nanopartículas de Magnetita Superparamagnéticas por Precipitação Simultânea}

As nanoparticulas de magnetita foram obtidas por processo de precipitação simultânea, segundo a equação (11):

$$
\mathrm{Fe}^{2+}+2 \mathrm{Fe}^{3+}+8 \mathrm{OH}^{-} \longrightarrow \begin{gathered}
\mathrm{FeO}^{2+} \mathrm{Fe}_{2} \mathrm{O}_{3}+4 \mathrm{H}_{2} \mathrm{O} \\
\text { (magnetita ou ferrita de ferro) }
\end{gathered}
$$

Para isso, pesaram-se $8,7 \mathrm{~g}$ de $\mathrm{FeCl}_{2} \cdot 4 \mathrm{H}_{2} \mathrm{O}$ (cloreto de ferro II tetrahidratado) e $23,4 \mathrm{~g}$ de $\mathrm{FeCl}_{3} .6 \mathrm{H}_{2} \mathrm{O}$ (cloreto de ferro III hexahidratado), que foram dissolvidos em $200 \mathrm{~mL}$ de água, separadamente. Após juntar as duas soluções em um béquer de $1 \mathrm{~L}$, adicionou-se lentamente uma solução de $\mathrm{NaOH} 5$ mol. $\mathrm{L}^{-1}$ até atingir o $\mathrm{pH}$ próximo a 11.

O precipitado preto formado - a magnetita - foi deixado em repouso sobre um imã por uma noite.

Em seguida separou-se o precipitado decantado, vertendo a parte líquida. Lavou-se repetidamente o precipitado, acrescentando-se água, agitandose manualmente o sistema e deixando-se em repouso. A cada nova decantação. o sobrenadante era separado com o auxílio de sucção e descartado. A lavagem foi realizada até o sobrenadante atingir um $\mathrm{pH}$ entre 6 e 7 .

A magnetita obtida foi dividida em duas partes, onde uma delas foi lavada duas vezes com metanol e ambas foram deixadas para secar a temperatura ambiente.

Durante a secagem, a magnetita foi agitada periodicamente para que os grãos se mantivessem soltos.

A parte lavada com metanol apresentou uma secagem mais rápida ( 3 dias) do que a parte não lavada com metanol (2 semanas). 
A FIG. 6 representa a seqüência de preparação das nanopartículas de magnetita.

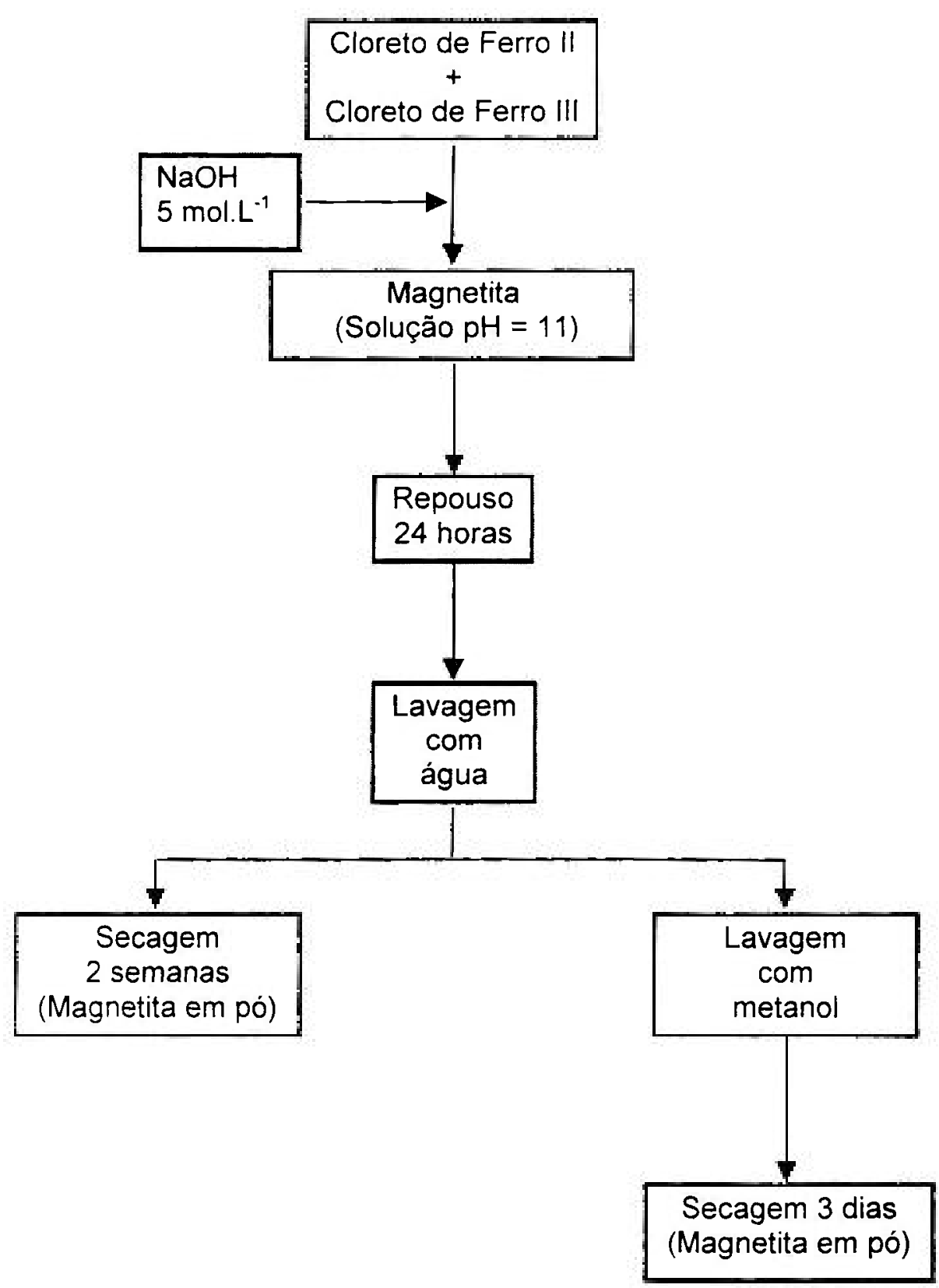

FIGURA 6 - Seqüência de Preparação das Nanopartículas de Magnetita.

As magnetitas secas apresentaram-se como um pó cristalino, de cor preta e com propriedade magnética, conforme mostram as FIG. 7 e 8 , respectivamente. As partículas de tamanho entre 30 a 80 mesh, obtidas por 
separação granulométrica, foram guardadas em recipientes para estudos posteriores.

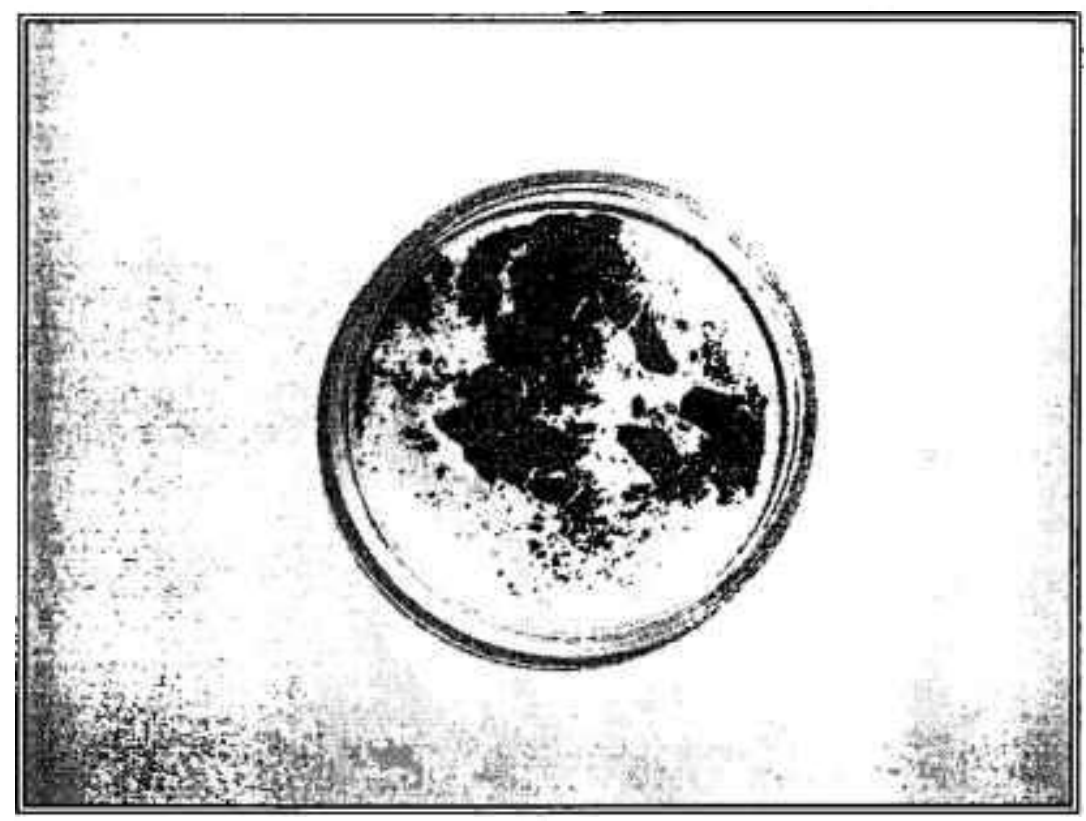

FIGURA 7 - Partículas de Magnetita Obtidas por Processo de Precipitação Simultânea.

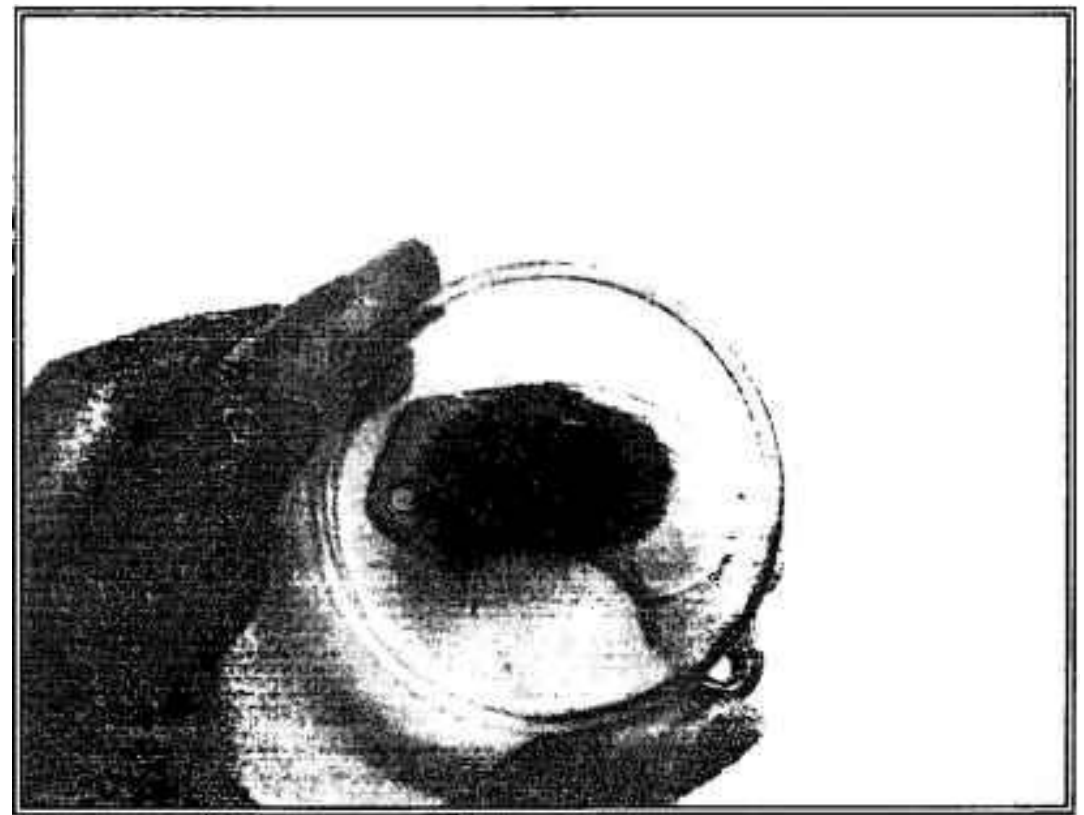

FIGURA 8 - Particulas de Magnetita Sob Ação de um Campo Magnético de um Imã. 


\subsection{Preparação de Soluções de Urânio}

\subsubsection{Preparação de Soluções de Urânio em Diferentes pH a partir de Solução Padrã̀o}

A partir de uma solução padrão de $U$ (nitrato de uranilo 130,07 $\pm 0,01$ g. $\mathrm{L}^{-1}$ ), de procedência do Centro de Química e Meio Ambiente (CQMA) do IPEN, foram preparadas, por diluição, soluções com concentração de $U 100 \pm 1 \mathrm{mg} \cdot \mathrm{L}^{-1}$, para $\mathrm{pH} 2,3,4,5$ e 10.

Trinta e cinco microlitros de solução padrão de $U$ foram diluídos em 45 $\mathrm{mL}$ de $\mathrm{H}_{2} \mathrm{O}$ e o pH acertado ao valor desejado com adição de $\mathrm{HNO}_{3}$ ou $\mathrm{NaOH}$.

\subsubsection{Preparação de Soluções de Urânio com Concentrações Diferentes a partir de Solução Padrão}

A partir de uma solução padrão de $U$ (nitrato de uranilo130,07 $\pm 0,01$ g. $\mathrm{L}^{-1}$ ), foram preparadas soluções de $\mathrm{U} 50 \mathrm{mg} \cdot \mathrm{L}^{-1}, 100 \mathrm{mg} \cdot \mathrm{L}^{-1}, 150 \mathrm{mg} \cdot \mathrm{L}^{-1}, 200$ $\mathrm{mg} \cdot \mathrm{L}^{-1}, 300 \mathrm{mg} \cdot \mathrm{L}^{-1}, 400 \mathrm{mg} \cdot \mathrm{L}^{-1}$ e $500 \mathrm{mg} \cdot \mathrm{L}^{-1} . \mathrm{O} \mathrm{pH}$ foi fixado em pH 5. O ajuste de $\mathrm{pH}$ foi realizado com solução de $\mathrm{NaOH}$.

\subsection{Processo de Adsorção}

Todos os estudos de adsorção foram realizados utilizando o ensaio em copo ou batelada ("batch method"). Agitou-se mecanicamente um frasco contendo uma determinada massa de magnetita e $1 \mathrm{~mL}$ de solução de nitrato de uranilo durante um determinado tempo. Após o equilibrio, a magnetita foi retida no fundo do frasco com auxilio de um imã e a fase aquosa foi separada para análise do $U$ remanescente, por espectrofotometria. Por diferença de concentração de $U$ entre a solução inicial e a fase aquosia sobrenadante, determinou-se a quantidade de $U$ 
adsorvida pela magnetita. A FIG. 9 mostra o esquema do procedimento experimental utilizado para os estudos de adsorção. Os experimentos de adsorção foram realizados em duplicata e com a magnetita lavada com metanol. Somente no estudo de isotermas de adsorção utilizam-se as duas agnetitas, lavadas com metanol e com água.

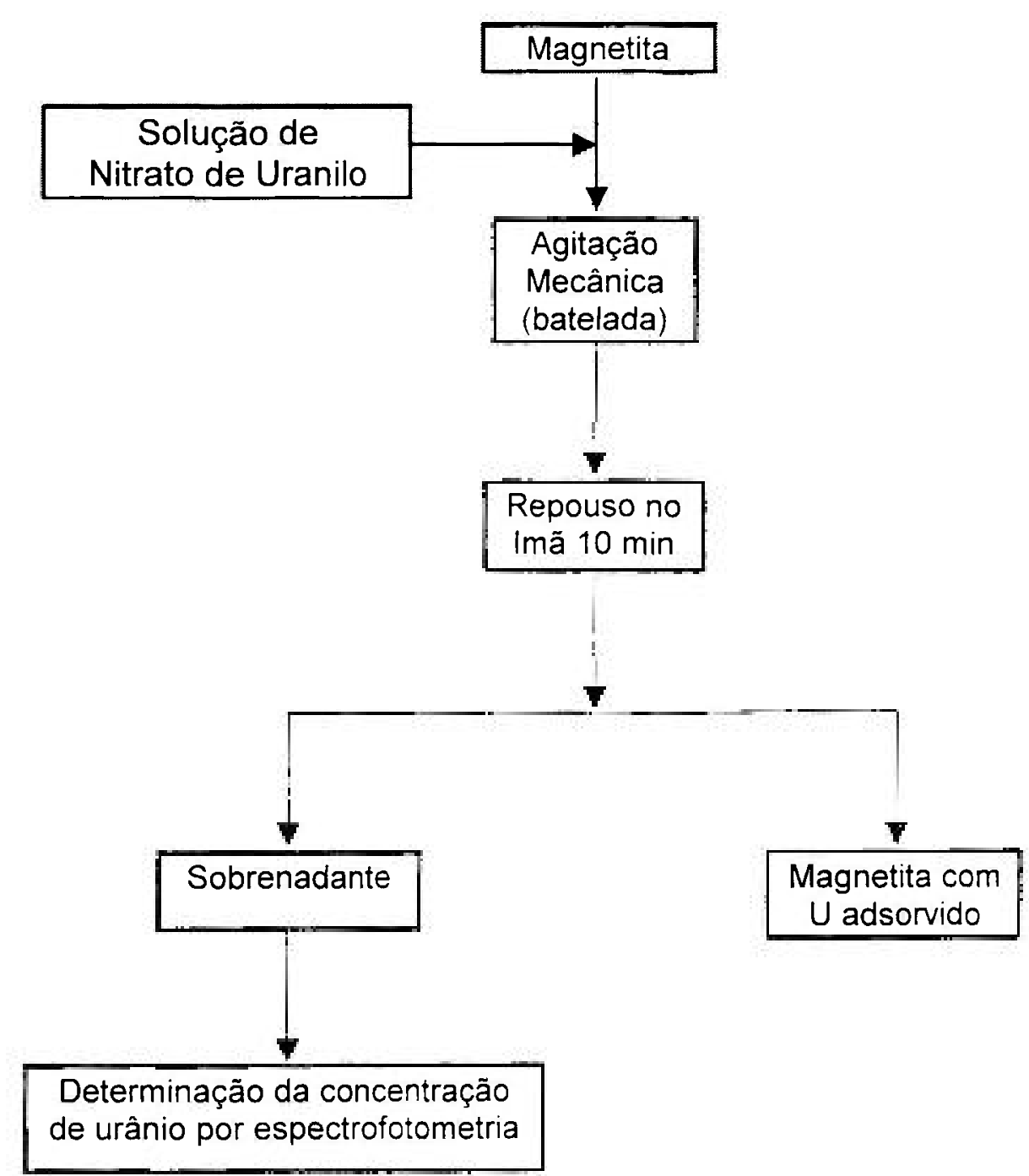

FIGURA 9 - Procedimento Experimental para Estudos de Adsorção.

\subsection{Análise de $\mathrm{UO}_{2}{ }^{2+}$ em Arsenazo III por Espectrofotometria}

O controle analítico dos ions de $U$ foi realizado pelo método de Arsenazo III, utilizando-se um Espectrofotômetro de UV-visivel. modelo B582, Micronal. 
Aliquotas entre 100 e $500 \mu \mathrm{L}$ de solução de urânio (sobrenadante ou fase aquosa), provenientes do estudo de adsorção, conforme descrito no item 4.4, foram colocadas em um balão volumétrico de $5 \mathrm{~mL}$. Adicionaram-se à alicuvta, na sequêtncia, $150 \mu \mathrm{L}$ de ácido ascórbico $15 \mathrm{~g} \cdot \mathrm{L}^{-1}, 100 \mu \mathrm{L}$ de ácido nirros 0,56 mol. $L^{-1} \cdot 1,5 \mathrm{~mL}$ de arsenazo III 0,06\% e completou-se com água destilaca [76].

Realizou-se a leitura de absorbância no espectrofotômetro no comprimento de onda igual a $650 \mathrm{~nm}$ e a concentração de $U$ foi determinada utilizando-se a curva de calibração. Todas as medidas foram realizadas em duplicata. A FIG. 10 ilustra o espectro de absorção do complexo $\mathrm{UO}_{2}{ }^{2+}$ - arsenazo III obtida para determinação do comprimento de onda de máxima absorbância, que foi de $650 \mathrm{~nm}$ e a FIG. 11 mostra a curva de calibração de $\mathrm{UO}_{2}{ }^{2+} \mathrm{em}$ arsenazo III $0,06 \%$, utilizada no presente trabalho, a qual foi obtida variando-se as massas em $1 \mu \mathrm{g}, 5 \mu \mathrm{g}, 10 \mu \mathrm{g}, 15 \mu \mathrm{g}, 20 \mu \mathrm{g}, 25 \mu \mathrm{g}$ e $30 \mu \mathrm{g}$ de urânio em relação às suas respectivas absorbâncias. A equação da reta encontrada foi $y=0,0545 x+$ 0,0086 e o coeficiente de correlação linear $r^{2}=0,9992$. O limite de detecção encontrado foi de $0,5 \mu \mathrm{g}$.

1.0

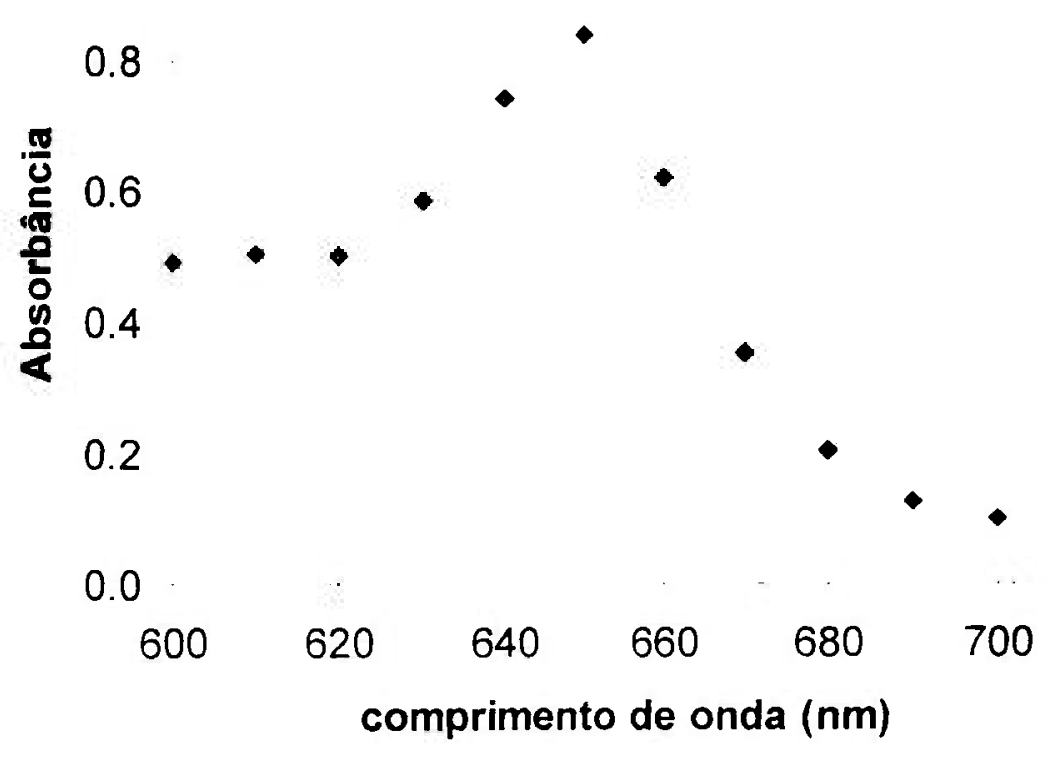

FIGURA 10 - Relação entre Absorbância e o Comprimento de Onda $(\mathrm{nm})$ do Complexo $\mathrm{UO}_{2}{ }^{24}$ - Arsenazo III. 


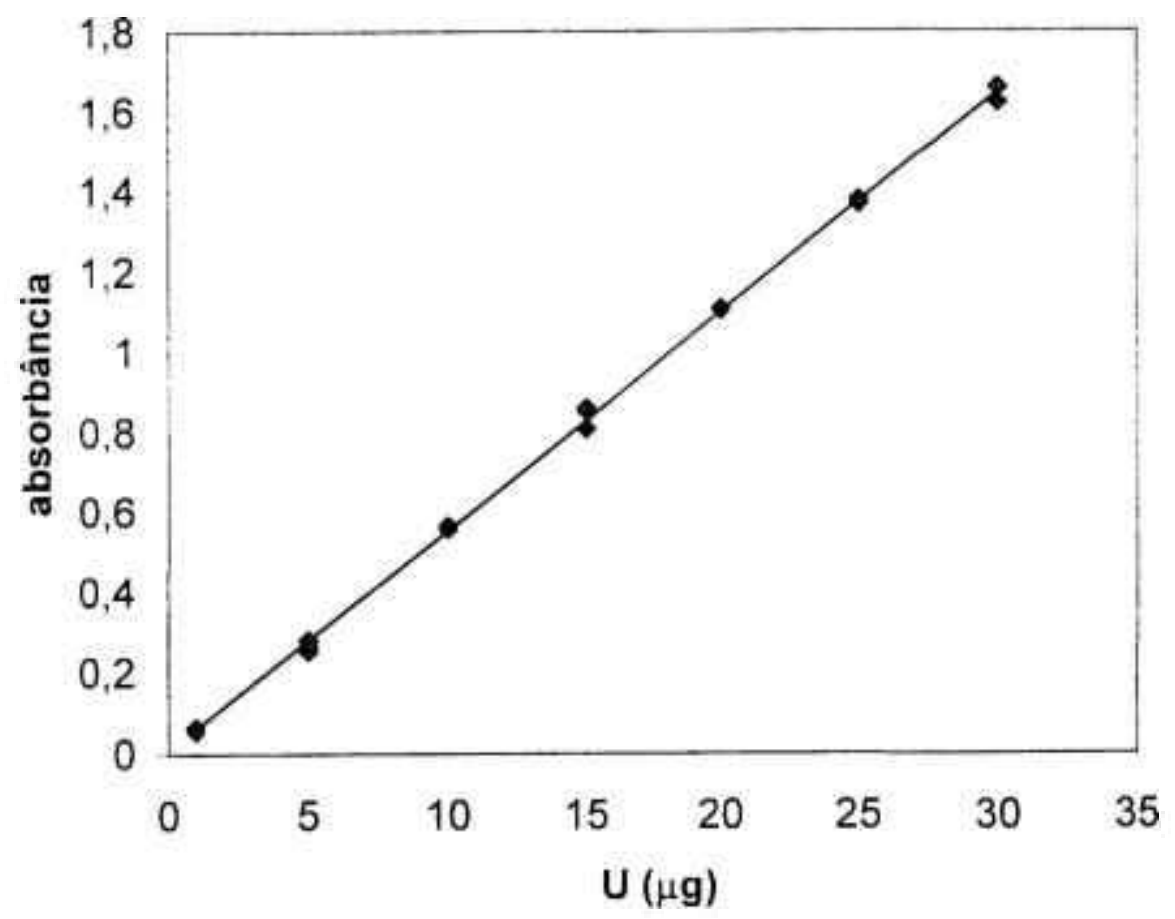

FIGURA 11 - Curva de Calibração de $\mathrm{UO}_{2}{ }^{2+}$ em Arsenazo III 0,06\%, $\lambda=650 \mathrm{~nm}$ (balão $=5 \mathrm{~mL}$ ). 


\section{RESULTADOS E DISCUSSÃO}

\subsection{Caracterização das Nanopartículas de Magnetita}

\subsubsection{Difração de Raios-X}

A análise por difração de raios- $X$ foi realizada com a finalidade de identificar $\circ$ composto preto e magnético preparado segundo o procedimento descrito no item 4.2 .

A FIG. 12 mostra o difratograma de raios-X obtido. Os picos encontrados na figura e comparados com a base de dados JCPDS - JCDD19629 , conforme FIG. 13, confirmam a presença de cristais de magnetita.

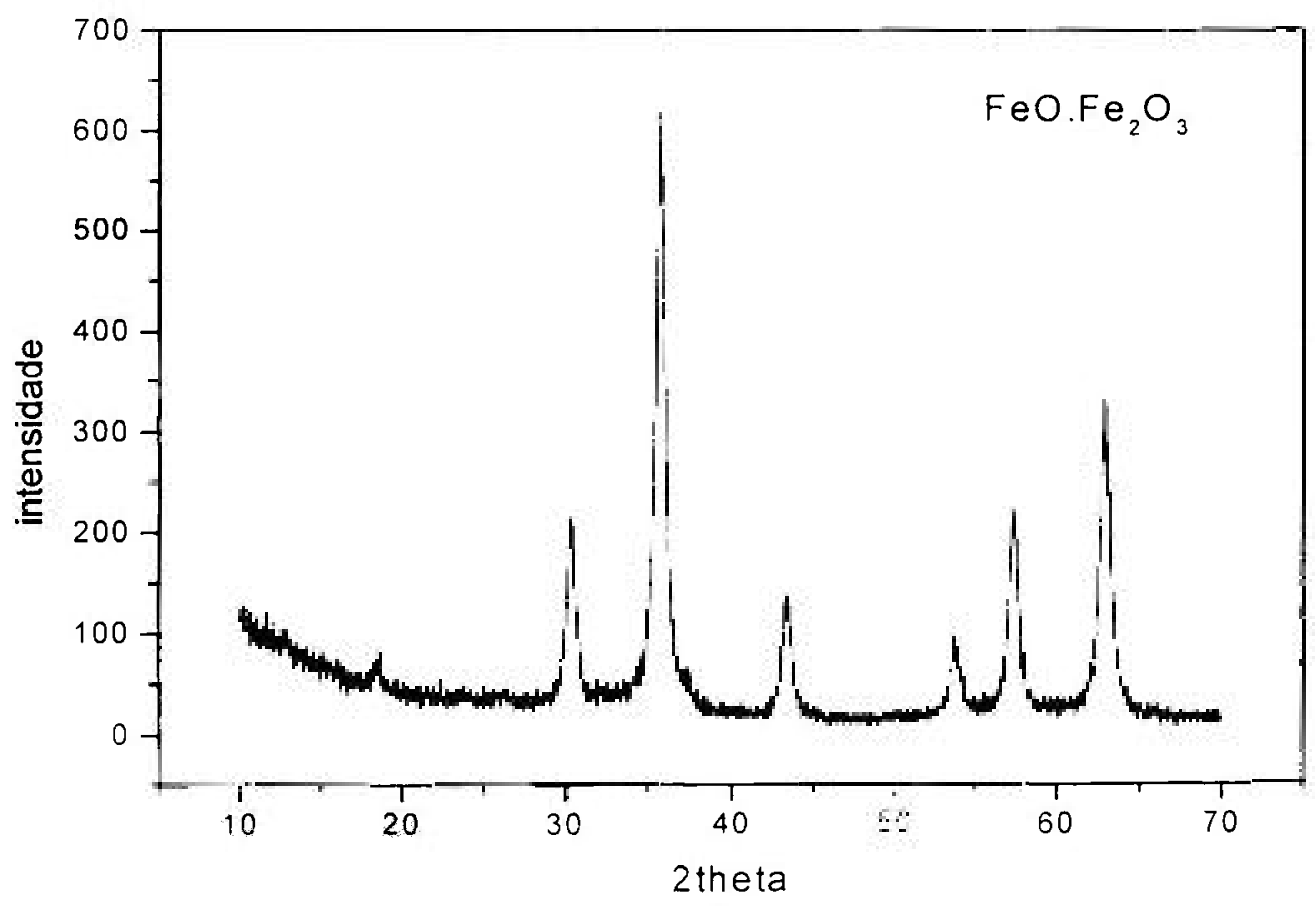

FIGURA 12 - Difratograma das Nanoparticulas de Magnetita. Radiação Incidente de CuKa. 


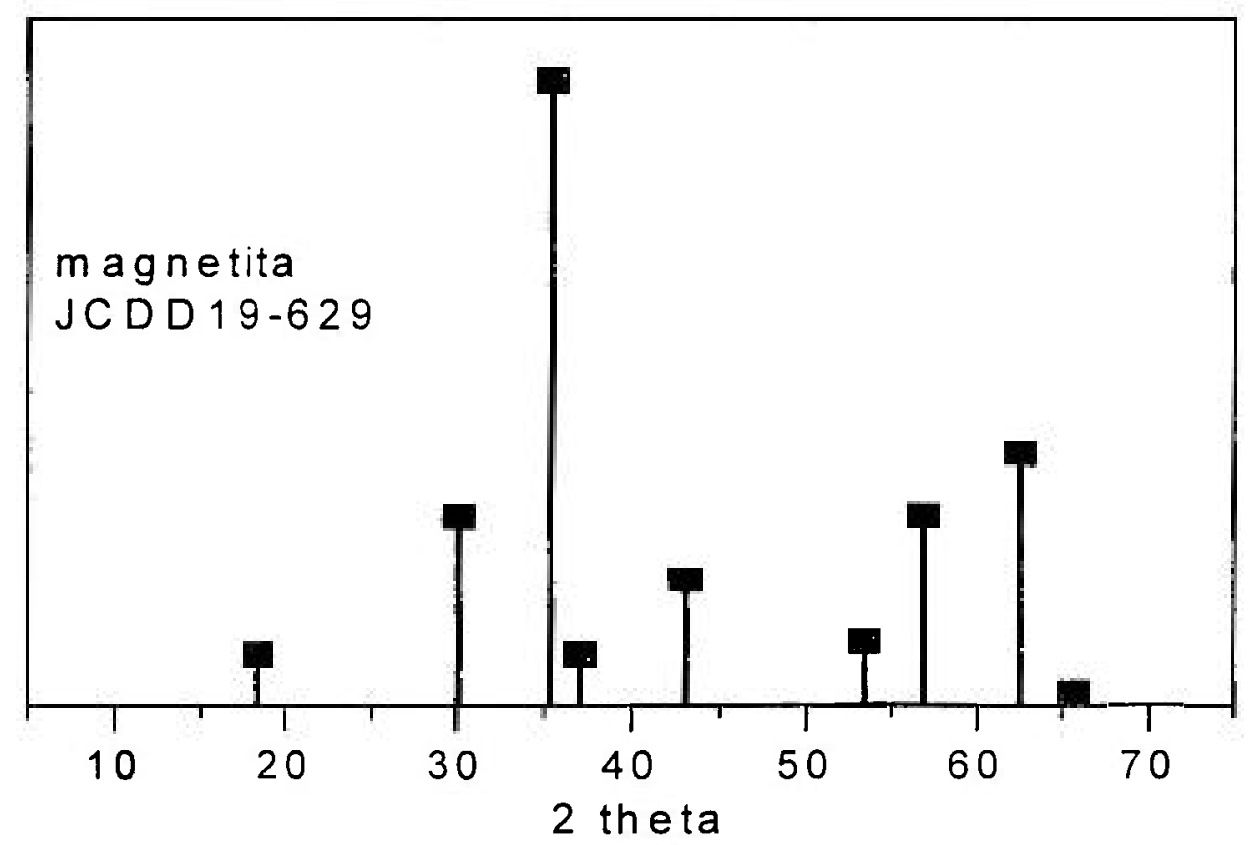

FIGURA 13 - Difratograma da Magnetita. Base de dados JCPDS - JCDD19-629.

\subsubsection{Medidas Magnéticas}

As particulas de magnetita exibiram uma forte magnetização com uma excelente resposta magnética como mostra a FIG. 14, de forma que para estudar o seu comportamento magnético realizaram-se medidas de magnetização.

Como pode ser observado na FIG. 15, as partículas de magnetita não apresentaram histerese, sendo completamente reversiveis a $27^{\circ} \mathrm{C}$. Elas responderam a um campo magnético mas não reteram a magnetização com a retirada do mesmo.

Este comportamento está de acordo com a propriedade superparamagnética observada em nanopartículas de magnetita de tamanho menor do que $26 \mathrm{~nm}$. como verificado em estudos já realizados [77]. 


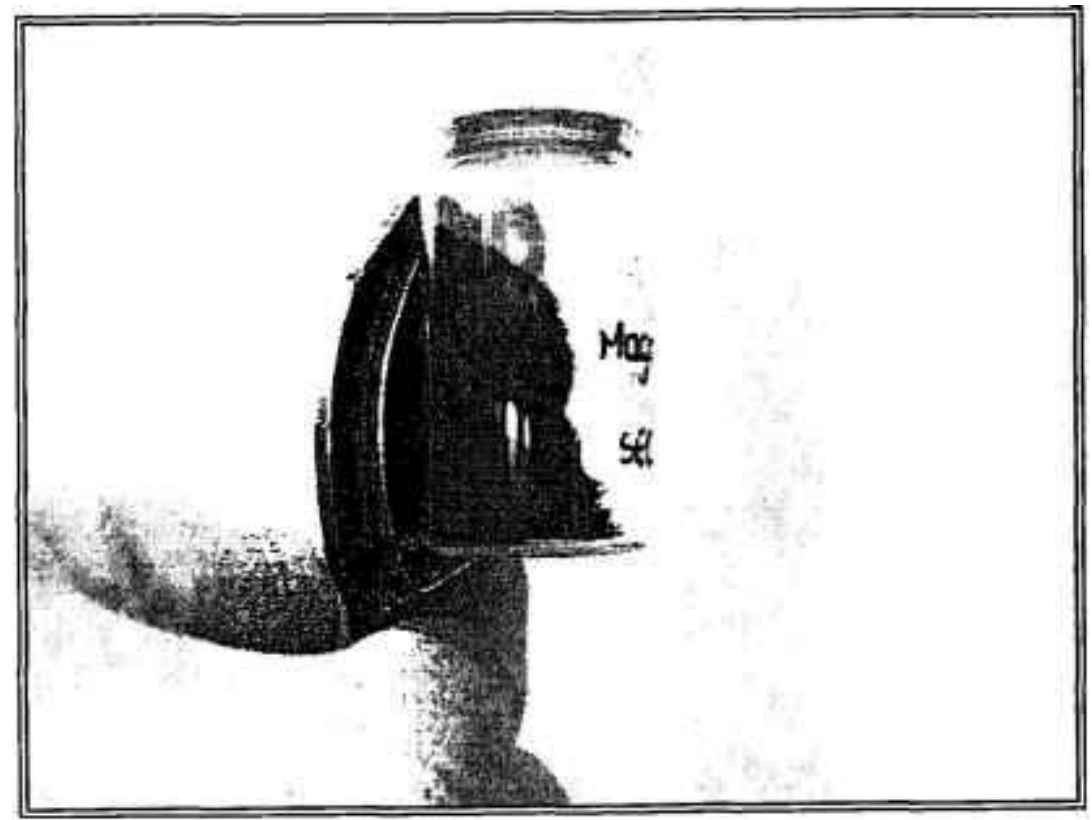

FIGURA 14 - Nanopartículas de Magnetita Atraídas por um Imã.

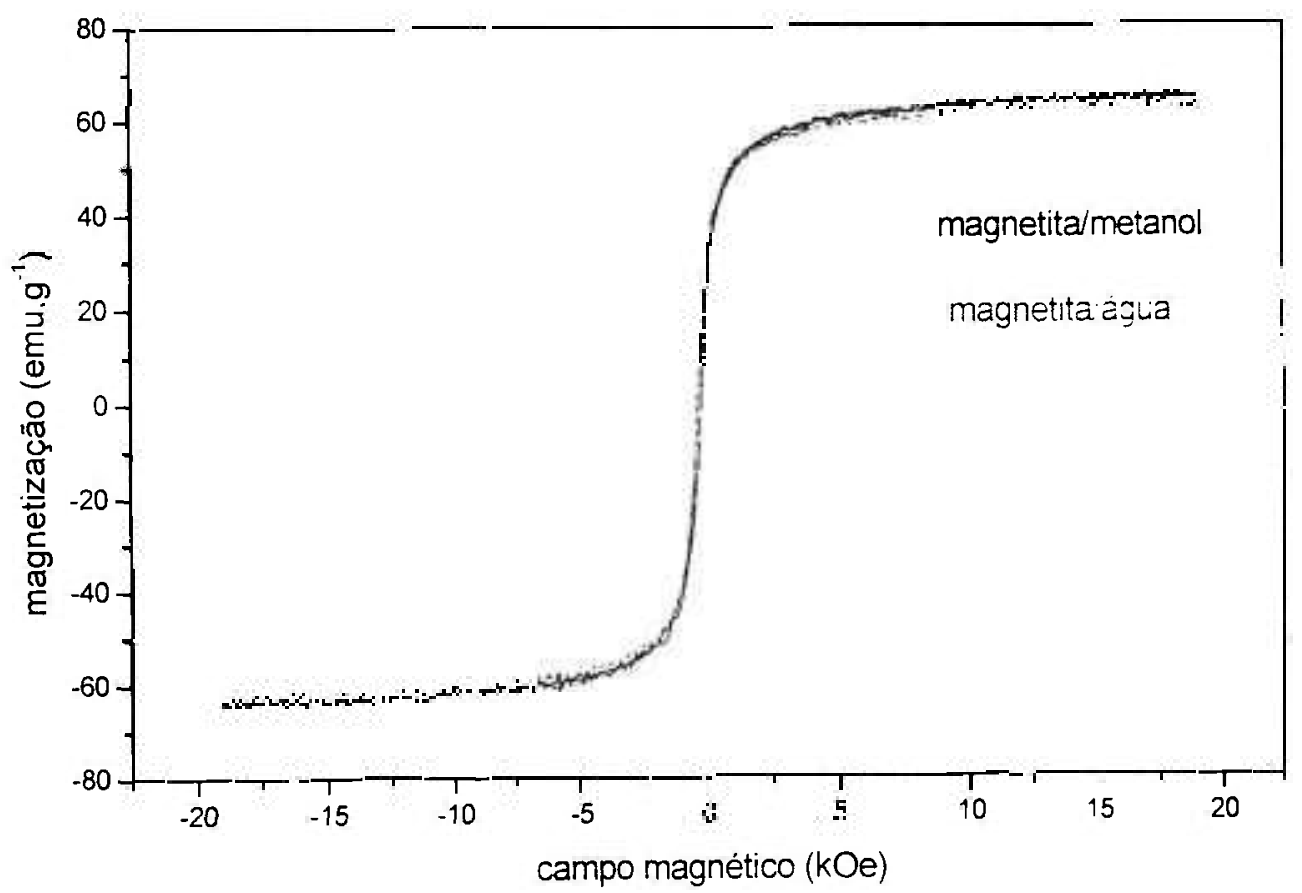

FIGURA 15 - Curva de Magnetização das Nanoparticulas de Magnetita. 


\subsubsection{Microscopia Eletrônica de Varredura}

Realizou-se a análise de MEV com o propósito de avaliar a morfologia das particulas de magnetita. A micrografia obtida, ilustrada na FIG. 16 mostra partículas distribuídas de formas e tamanhos irregulares, observando-se grãos menores de magnetita impregnados em grãos maiores.

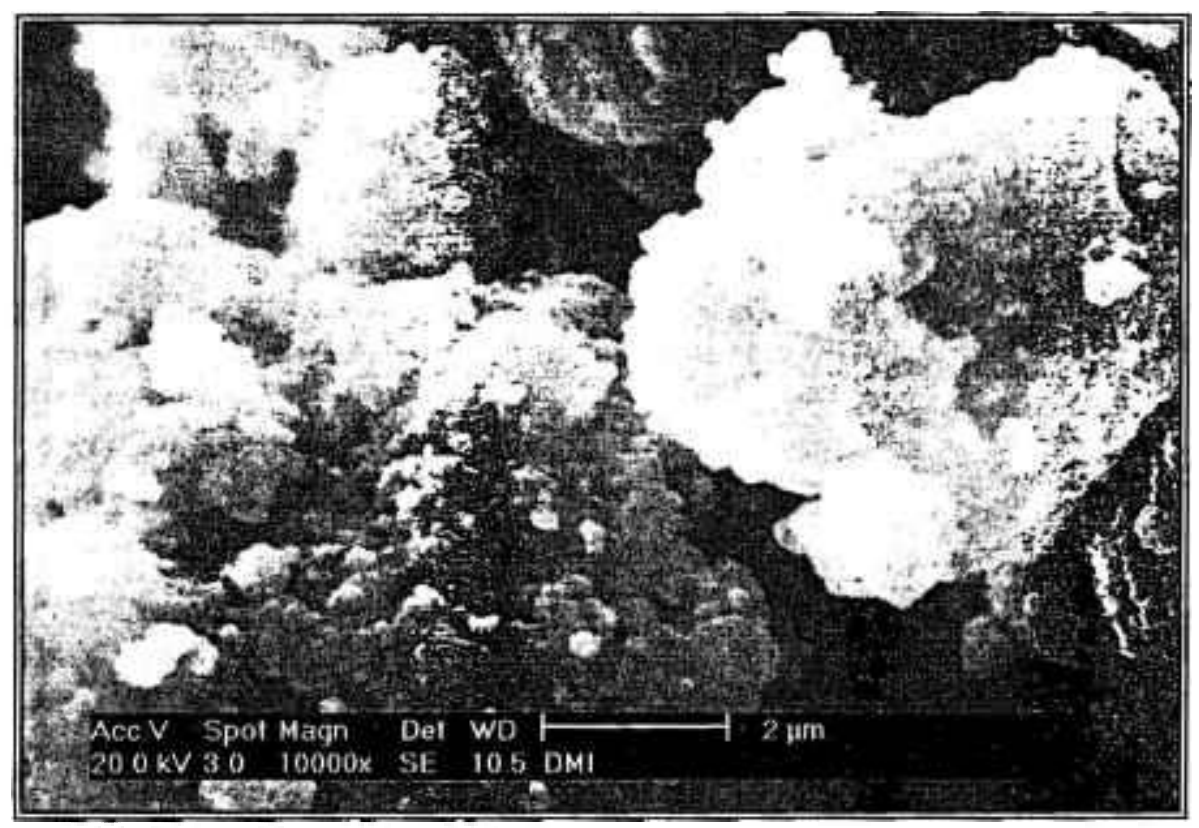

FIGURA 16 - Micrografia das Nanopartículas de Magnetita por MEV.

\subsection{Estudo de Adsorção}

Influência do $\mathrm{pH}$ na Adsorção de $\mathrm{UO}_{2}{ }^{2+}$. Realizaram-se os experimentos em batelada, segundo o procedimento descrito no item 4.4, com soluções de nitrato de uranilo $100=1 \mathrm{mg} \cdot \mathrm{L}^{-1}$, variando-se o $\mathrm{pH}$ no intervalo de 2 a 10. Utilizaram-se $40 \mathrm{mg}$ de magnetita, $30 \mathrm{~min}$ de agitação e velocidade de agitação de $360 \mathrm{rpm}$.

Os resultados apresentados na FIG. 17 mostram que a "s de remoção aumentou com o aumento do pH no intervalo entre 2 e 5 . Nota-se no pH $10 \mathrm{um}$ considerável decréscimo na $\%$ de remoção. Atribui-se a queda no $\mathrm{pH} 10$ à formação de espécies de hidroxi-uranilo negativamente carregado. como ions $\mathrm{UO}_{2}(\mathrm{OH})_{3}{ }^{-}$de baixa adsortividade e no caso do $\mathrm{pH} 2$, não apresentou valores de 
absorbância reprodutiveis em função da dissolução da magnetita [16], provocada pela alta acidez, segundo a equação (12):

$$
\mathrm{FeO} . \mathrm{Fe}_{2} \mathrm{O}_{3}+8 \mathrm{H}^{+} \longrightarrow 2 \mathrm{Fe}^{3+}+\mathrm{Fe}^{2+}+4 \mathrm{H}_{2} \mathrm{O}
$$

Dos estudos preliminares, observou-se que entre $\mathrm{pH} 6$ e pH 9 ocorreu a precipitação de urânio por hidrólise, razão pela qual não foram realizados estudos para verificação da influência do pH neste intervalo.

Com base no exposto, os estudos deram continuidade em pH 4 e pH 5 em que se verificaram maiores porcentagens de remoção.

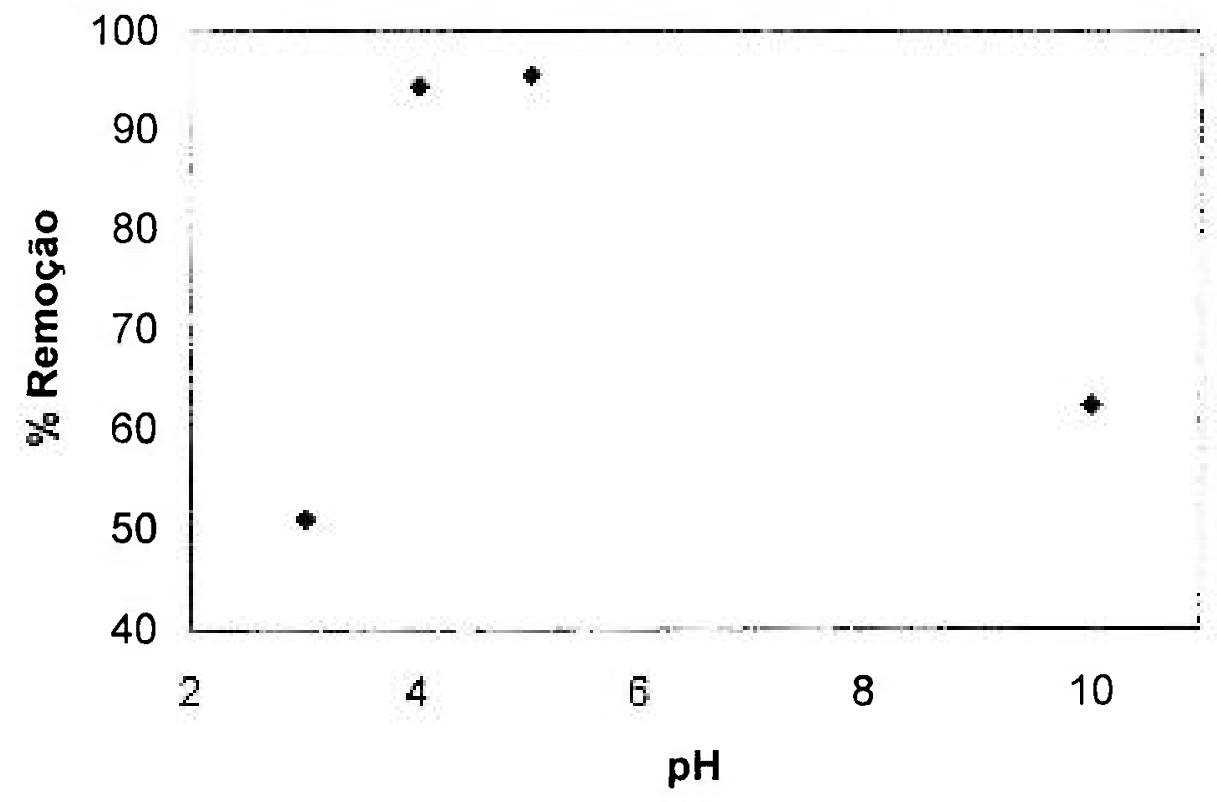

FIGURA 17 - Variação da \% de Remoção de $\mathrm{UO}_{2}{ }^{2+}$ pela Magnetita em Função da Variação do $\mathrm{pH}$.

Estudo de Dose de Magnetita. Neste estudo verificou-se a influência da massa de magnetita no processo de adsorção de ions $\mathrm{UO}_{2}{ }^{2+}$. A dose definida aqui. é a massa de magnetita por volume de solução de contato. Cada massa de magnetita, que variou de 5 a $40 \mathrm{mg}$, foi colocada em contato com $1 \mathrm{~mL}$ de solução de $U 100 \pm 1 \mathrm{mg} . \mathrm{L}^{-1}$ de $\mathrm{pH} 4$ e pH 5 , separadamente. Utilizaram-se tempo de agitação igual a $30 \mathrm{~min}$ e velocidade de $360 \mathrm{rpm}$. 
Os resultados apresentados na FIG. 18 mostram que a capacidade de adsorção da magnetita em pH 5 diminuiu exponencialmente com o aumento da dose de magnetita e com tendência a se tornar constante em doses acima de 40 g. $\mathrm{L}^{-1}$. Em pH 4, o decréscimo da capacidade de adsorção com aumento de dose não foi significativo.

Já na FIG. 19, observa-se um comportamento inverso, quanto maior a dose de magnetita maior a \% de remoção de $U$, como era previsto. Com base nesses dois comportamentos, para os estudos posteriores fixou-se a dose de magnetita a ser utilizada posteriormente em $15 \mathrm{~g} \cdot \mathrm{L}^{-1}$. É um valor que proporciona uma boa capacidade de adsorção, com uma \% de remoção de 40 a $80 \%$ para os $\mathrm{pH} 4$ e 5 , respectivamente. Doses de magnetita maiores ou iguais a $30 \mathrm{~g} \cdot \mathrm{L}^{-1}$, apesar de proporcionar uma remoção próxima de $100 \%$ não foram consideradas para poder verificar a influência de outros parâmetros de adsorção por variaçāo de \% de remoção. Entretanto, em processos de tratamento de rejeito sugere-se utilizar dose igual a $30 \mathrm{~g} . \mathrm{L}^{-1}$ de magnetita a qual proporciona a máxima remoção com uma capacidade de adsorção maior que para doses maiores.

Uma análise comparativa mostra também que o pH 5 é o melhor $\mathrm{pH}$ de trabalho, confirmando o estudo do $\mathrm{pH}$.

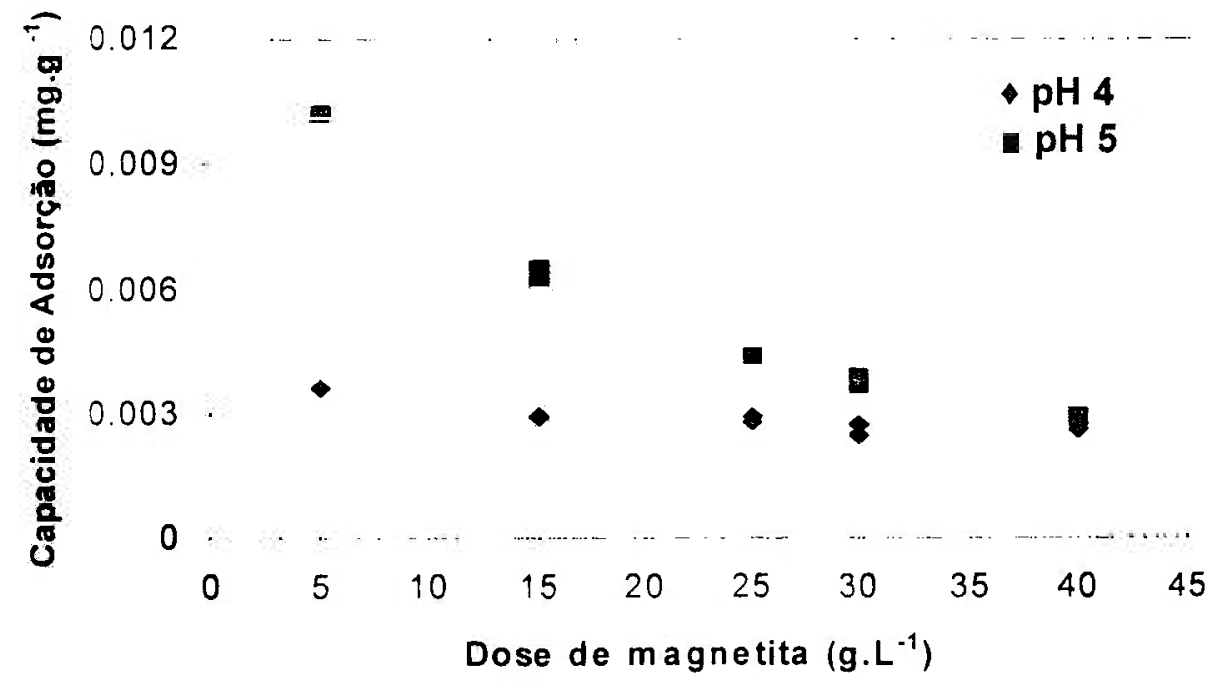

FIGURA 18 - Variação da Capacidade de Adsorção da Magnetita em Função da Dose para $\mathrm{UO}_{2}{ }^{2+}$, em Soluções Nitricas, a $27^{\circ} \mathrm{C}$. 


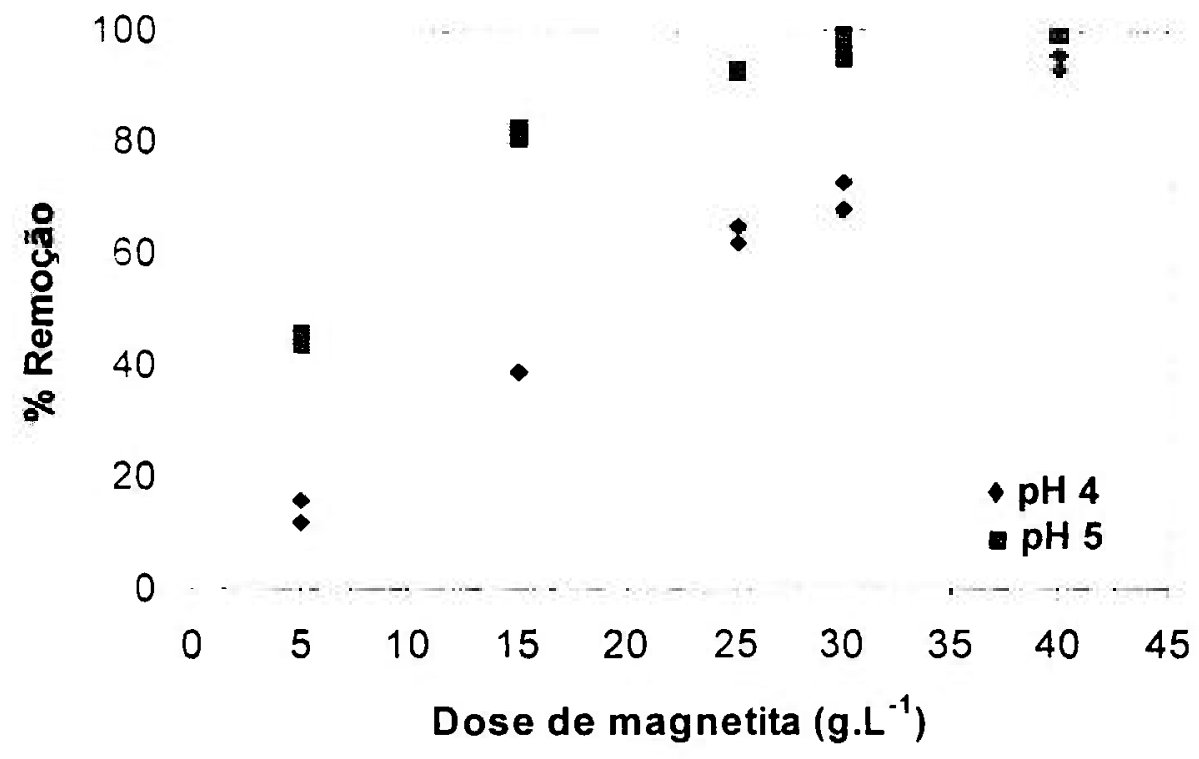

FIGURA 19 - Variação da \% de Remoção da Magnetita em Função da Dose para $\mathrm{UO}_{2}{ }^{2+}$ em Soluções Nitricas, a $27^{\circ} \mathrm{C}$.

\subsection{Cinética de Adsorção}

Este estudo envolve a relação de dependência da eficiência de adsorção com o tempo de agitação. A concentração de ions uranilo que permanece em solução decresce com o tempo até alcançar um valor constante além do qual não ocorre mais remoção de urânio da solução. Neste ponto, a quantidade de urânio que está sendo adsorvida pela magnetita está em estado de equilíbrio dinâmico com a quantidade que está dessorvendo. O tempo requerido para atingir este estado é chamado de tempo de equilibrio. No estudo de cinética verificou-se também a influência da velocidade de agitação no processo de adsorção.

Estudo do Tempo de Equilibrio. Fixou-se a massa de magnetita em $15 \mathrm{mg}$, equivalente a uma dose de $15 \mathrm{~g} \cdot \mathrm{L}^{-1}$ e variou-se o tempo de agitação entre 10 e 60 minutos. Os experimentos foram realizados em soluções de $U 100 \pm 1$ $\mathrm{mg} . \mathrm{L}^{-1}$ de $\mathrm{pH} 4$ e pH 5 e com velocidade de agitação de $360 \mathrm{rpm}$. 
Os resultados apresentados na FIG. 20 mostram que a adsorção aumentou com o aumento do tempo de agitação, porém a partir de 40 minutos a $\%$ remoção tornou-se constante, atingindo o equilibrio. Com base nos resultados apresentados, observou-se que o tempo de equilibrio independe do $\mathrm{pH}$ da solução, confirmado pelos estudos realizados pelo Missana e colaboradores [78].

Para o estudo de velocidade de agitação fixou-se o pH da solução em 5 e o tempo de agitação em $40 \mathrm{~min}$.

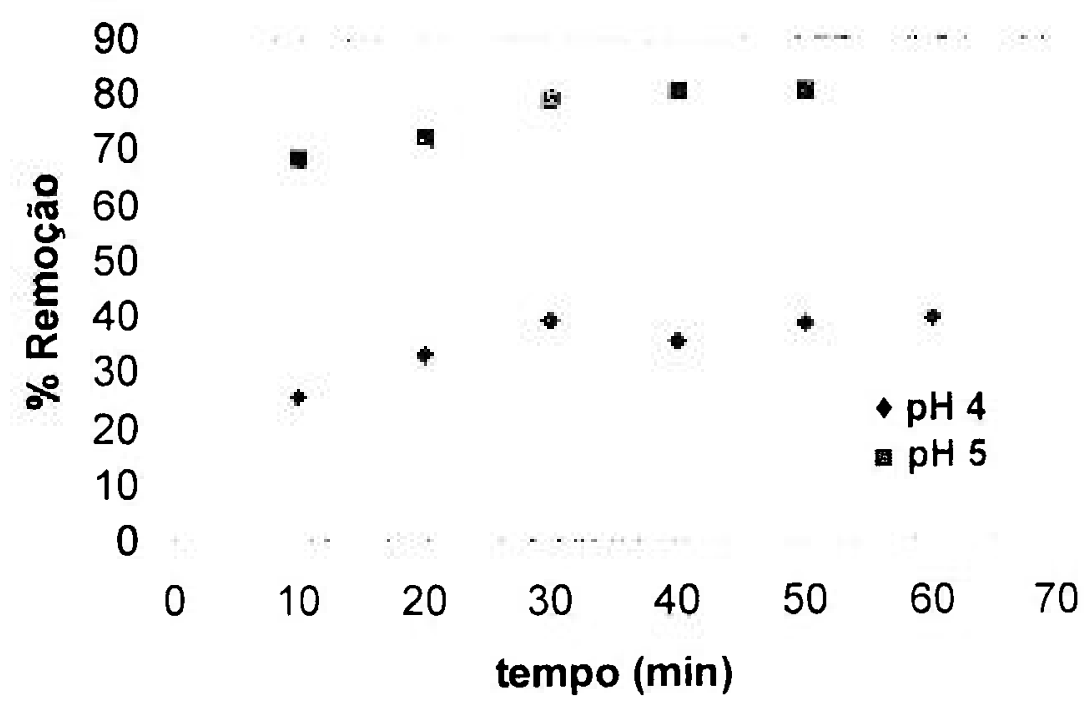

FIGURA 20 - Variação da \% de Remoção de $\mathrm{UO}_{2}{ }^{2+}$ de Soluções Nitricas, em Função do Tempo de Agitação.

Efeito da Velocidade de Agitação. Com uma solução de nitrato de uranilo $100 \pm 1 \mathrm{mg} \cdot \mathrm{L}^{-1}$ de $\mathrm{pH} 5$, uma massa de magnetita de $15 \mathrm{mg}$ e tempo de agitação em 40 minutos, estudaram-se três velocidades de agitação. A agitação é necessária para que ocorra uma homogeneização na superficie de contato.

Os resultados apresentados na FIG. 21, mostram que a adsorção ieve um pequeno aumento com o aumento da velocidade de agitação, atingince. equilíbrio a partir de $300 \mathrm{rpm}$.

Em velocidade baixa, de $100 \mathrm{rpm}$, nota-se uma imprecisão nas medidas de \% de remoção, presumindo-se uma agitação não homogênea e 
insuficiente para um tempo de equilibrio de 40 minutos. A baixa velocidade de agitação pode ser compensada com o aumento do tempo de agitação.

90

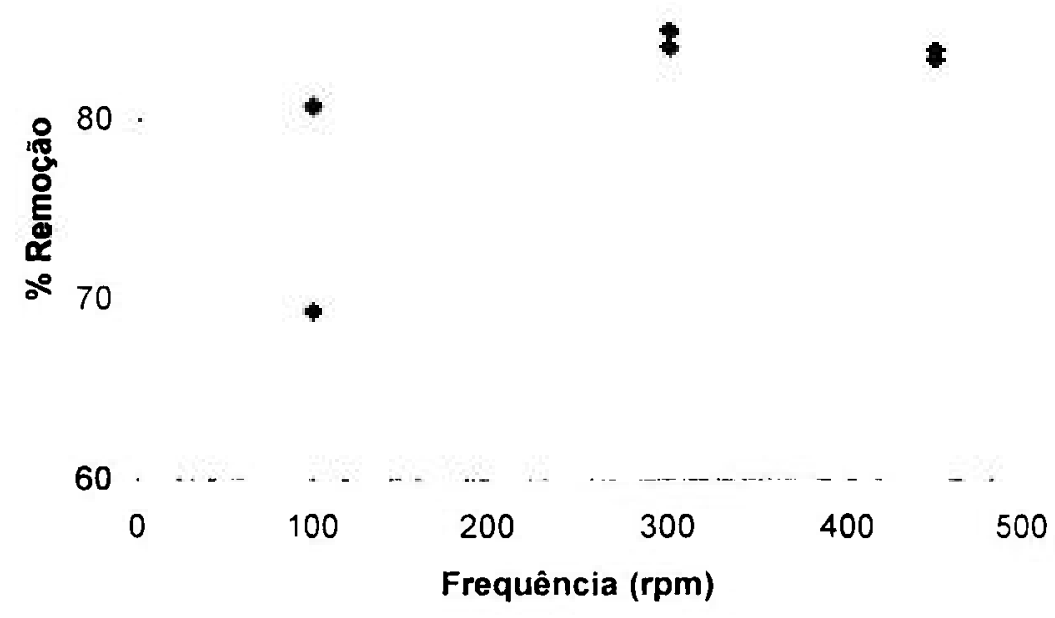

FIGURA 21 - Variação da \% de Remoção de $\mathrm{UO}_{2}{ }^{2+}$, de Soluções Nítricas de $\mathrm{pH}=5$, em Função da Freqüência de Agitação.

\subsection{Isotermas de Adsorção}

As isotermas de adsorção são fundamentais para geração e análise de parâmetros, que mostram os comportamentos do processo de adsorção, tais como tipos de adsorção. capacidade máxima de adsorção, intensidade de adsorção, se processo favorável ou não, entre outros. Os cálculos efetuados para obtenção desses parâmetros estão relacionados à equação das retas de Langmuir e Freundlich encontradas.

A isoterma de adsorção de $U$ na magnetita foi conduzida no intervalo de $50 \mathrm{mg} \cdot \mathrm{L}^{-1}$ a $500 \mathrm{mg} \cdot \mathrm{L}^{-1}$ de $U$ de solução nítrica, em pH 5 . Fixou-se a messsa de magnetita em $15 \mathrm{mg}$. $O$ tempo de agitação foi de 40 minutos. velocidade de agitação de $360 \mathrm{rpm}$ e temperatura ambiente. Estudaram-se cada magnetita separadamente, a magnetita lavada com metanol e a magnetita lavada com água, com a finalidade de compará-las quanto à capacidade de adsorção, se a reação é favorável ou não e a energia livre de Gibbs. 


\subsubsection{Isotermas de Adsorção de $\mathrm{UO}_{2}{ }^{2+}$, de Soluções Nítricas para a Magnetita Lavada com Metanol}

As FIG. 22 e 23 mostram as isotermas linearizadas de Langmuir e Freundlich, respectivamente, para $\circ \mathrm{UO}_{2}{ }^{2+}$ de soluções nítricas, para a magnetita lavada com metanol, baseadas nas equações (6) e (8) e nos valores de adsorção encontrados para as diferentes concentrações de $U$.

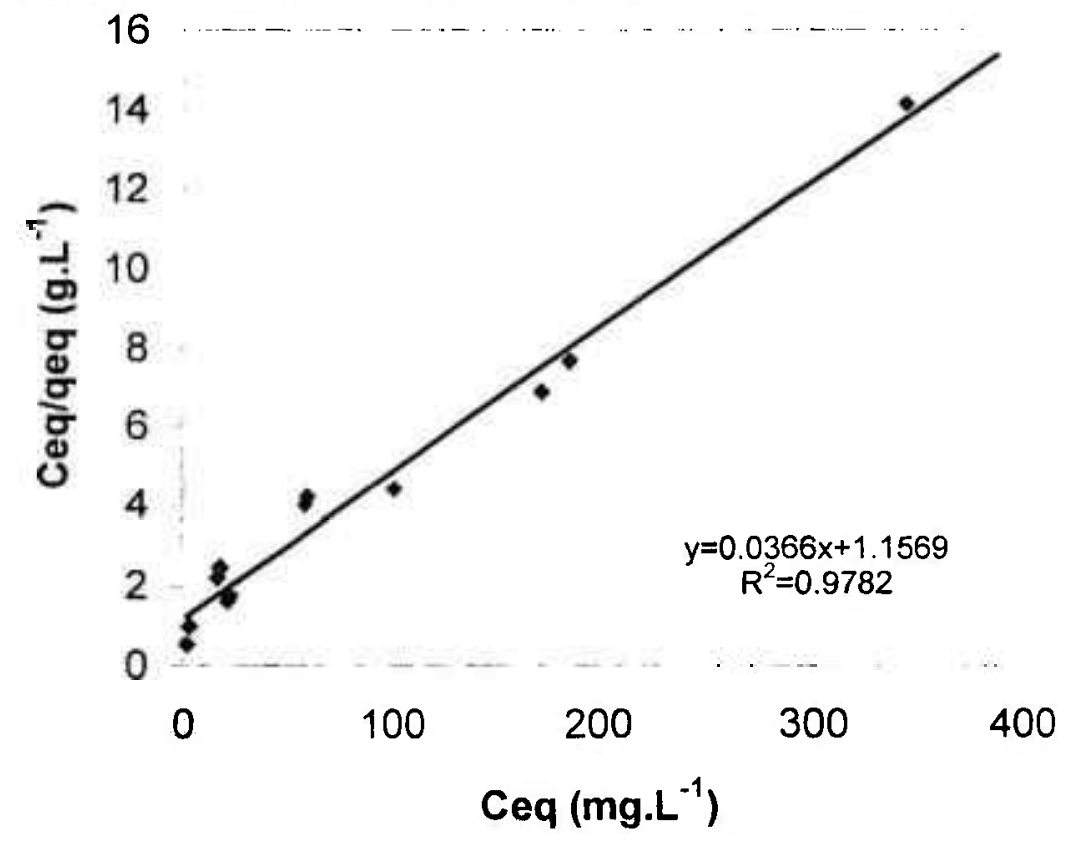

FIGURA 22 - Isoterma linearizada de Langmuir para $\mathrm{UO}_{2}{ }^{2+}$ de Soluções Nitricas em pH 5 para a Magnetita Lavada com Metanol, a $27^{\circ} \mathrm{C}$.

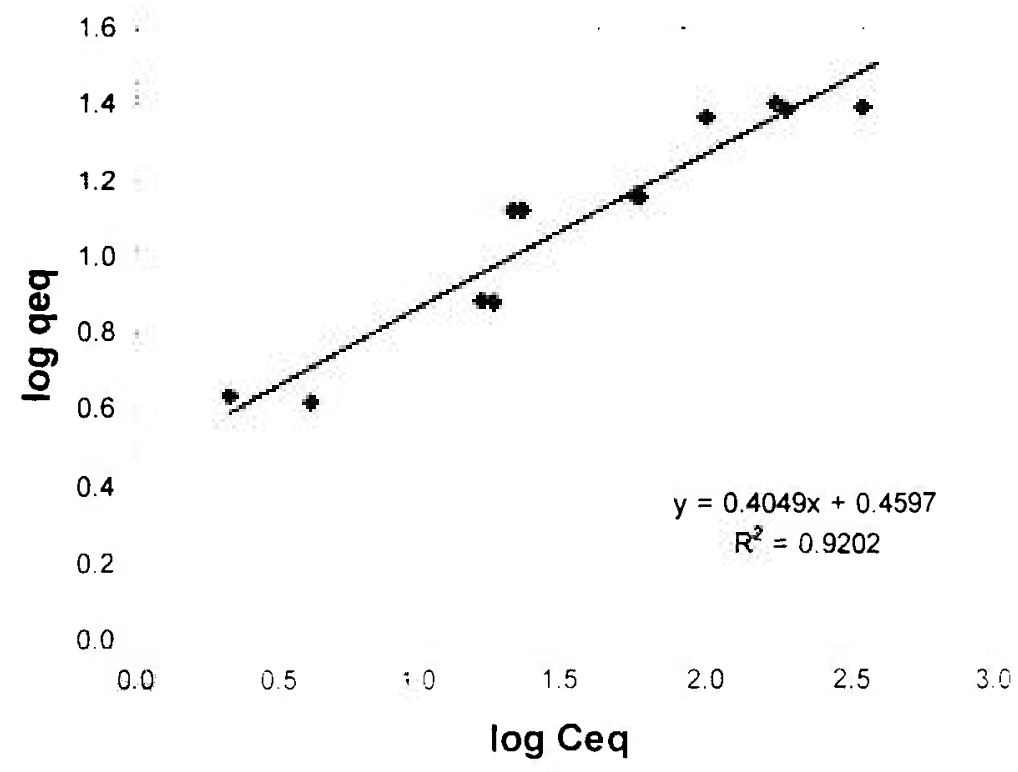

FIGURA 23 - Isoterma linearizada de Freundlich para $\mathrm{UO}_{2}{ }^{2+}$ de Soluções Nitricas em pH 5 para a Magnetita Lavada com Metanol, a $27^{\circ} \mathrm{C}$. 
Os valores da capacidade, da constante de Langmuir $\left(K_{L}\right)$, da intensidade de adsorção $(1 / n)$ e da constante de Freundlich $\left(K_{F}\right)$, foram determinados conforme descritos no item 3.4.4, para as equações neste caso, $y$ $=0,0366 x+1,1569$ da isoterma de Langmuir e $y=0,4049 x+0,4597$ da isoterma de Freundlich.

Conforme observa-se na TAB.2, tem-se que:

A capacidade máxima de adsorção é de $27 \pm 1 \mathrm{mg} \cdot \mathrm{g}^{-1}$, ou seja para cada grama de magnetita tem-se uma remoção de $27 \pm 1 \mathrm{mg}$ de ions $\mathrm{UO}_{2}{ }^{2+}$.

O valor de $1 / n$ é menor do que uma unidade indicando que o processo de adsorção do $\mathrm{UO}_{2}{ }^{2+}$ pela magnetita é favorável.

O modelo que melhor se aplicou ao processo de adsorção, segundo a forma linearizada, é o de Langmuir, pois apresentou maior concordância com os dados experimentais, verificado pelo alto valor de coeficiente de correlação linear $\left(r^{2}\right)$, indicando também, que o fenômeno ocorreu com formação de monocamada sobre a superfície do adsorvente.

TABELA 2 - Parâmetros de Langmuir e Freundlich para Adsorção de ĺons de Urânio de Meio Nitrico, pH 5, dose $15 \mathrm{~g} . \mathrm{L}^{-1}$, a $27^{\circ} \mathrm{C}$, para a Magnetita (com Metanol).

\begin{tabular}{lccccc}
\hline & $r^{2}$ & $\mathrm{~K}_{\mathrm{L}}$ & $\mathrm{Q}\left(\mathrm{mg} \cdot \mathrm{g}^{-1}\right)$ & $\mathrm{K}_{\mathrm{F}}$ & $1 / \mathrm{n}$ \\
\hline Langmuir & 0,9782 & 0,0316 & $27 \pm 1$ & - & - \\
Freundlich & 0,9202 & - & - & 2,88 & 0,4049 \\
\hline
\end{tabular}

A FIG. 24 mostra as isotermas de adsorção de Langmuir e Freundlich, levantados a partir das equações obtidas, confirmando que o melhor mezelo aplicado é o de Langmuir. 


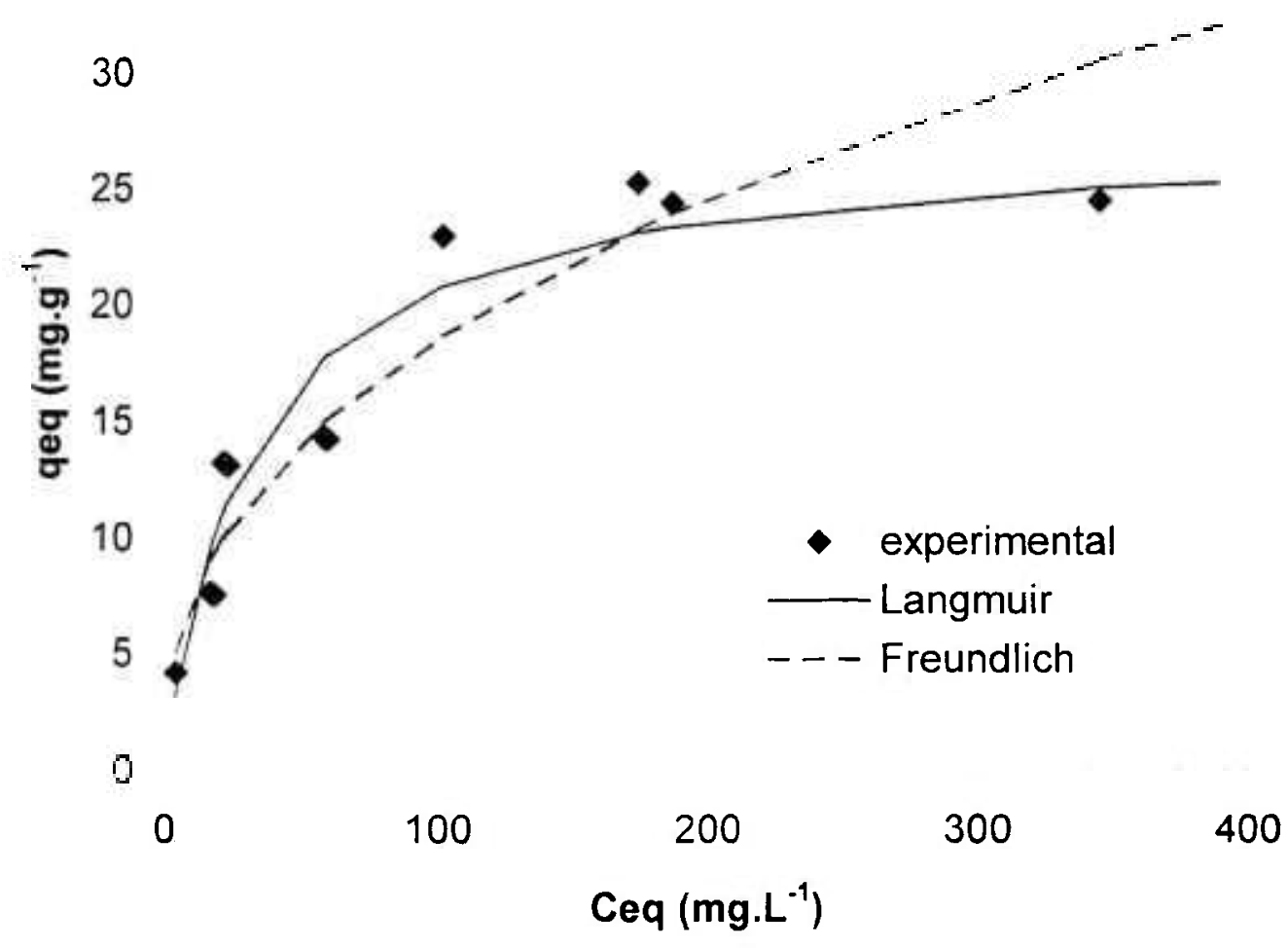

FIGURA 24 - Isotermas de Adsorção de Langmuir e Freundlich para $\mathrm{UO}_{2}{ }^{2+}$ de Soluções Nitricas em pH 5 para a Magnetita Lavada com Metanol, a $27^{\circ} \mathrm{C}$.

5.4.2 Isotermas de Adsorção de $\mathrm{UO}_{2}{ }^{2+}$, de Soluções Nítricas para a Magnetita Lavada com Água

As FIG. 25 e 26 mostram as isotermas linearizadas de Langmuir e Freundlich, respectivamente, para $\mathrm{UO}_{2}{ }^{2+}$ de soluções nitricas, $\mathrm{pH} 5$, para a magnetita lavada com água, baseadas nas equações (6) e (8) e nos valores de adsorção para diferentes concentrações de $U$, determinadas como no Esזudo anterior. 


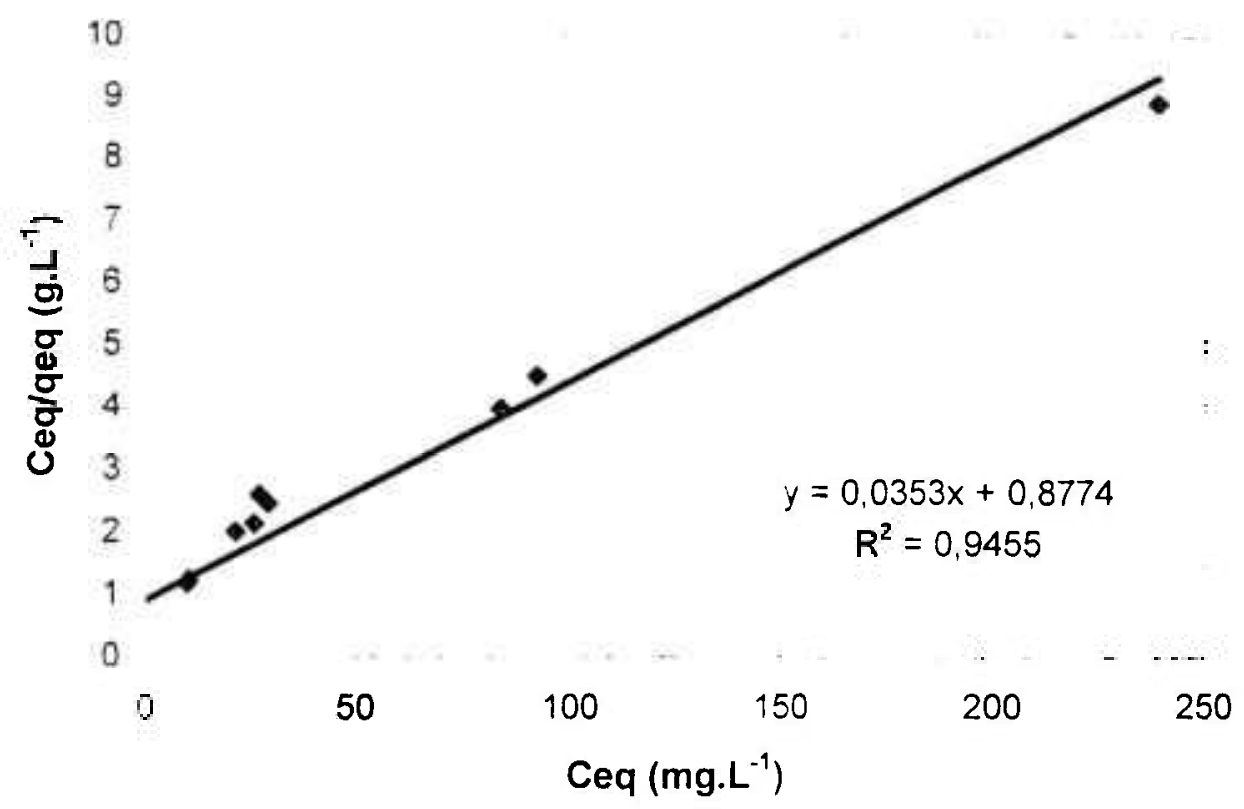

FIGURA 25 - Isoterma Linearizada de Langmuir para $\mathrm{UO}_{2}{ }^{2+}$ de Soluções Nitricas em pH 5 para a Magnetita Lavada com Água, a $27^{\circ} \mathrm{C}$.

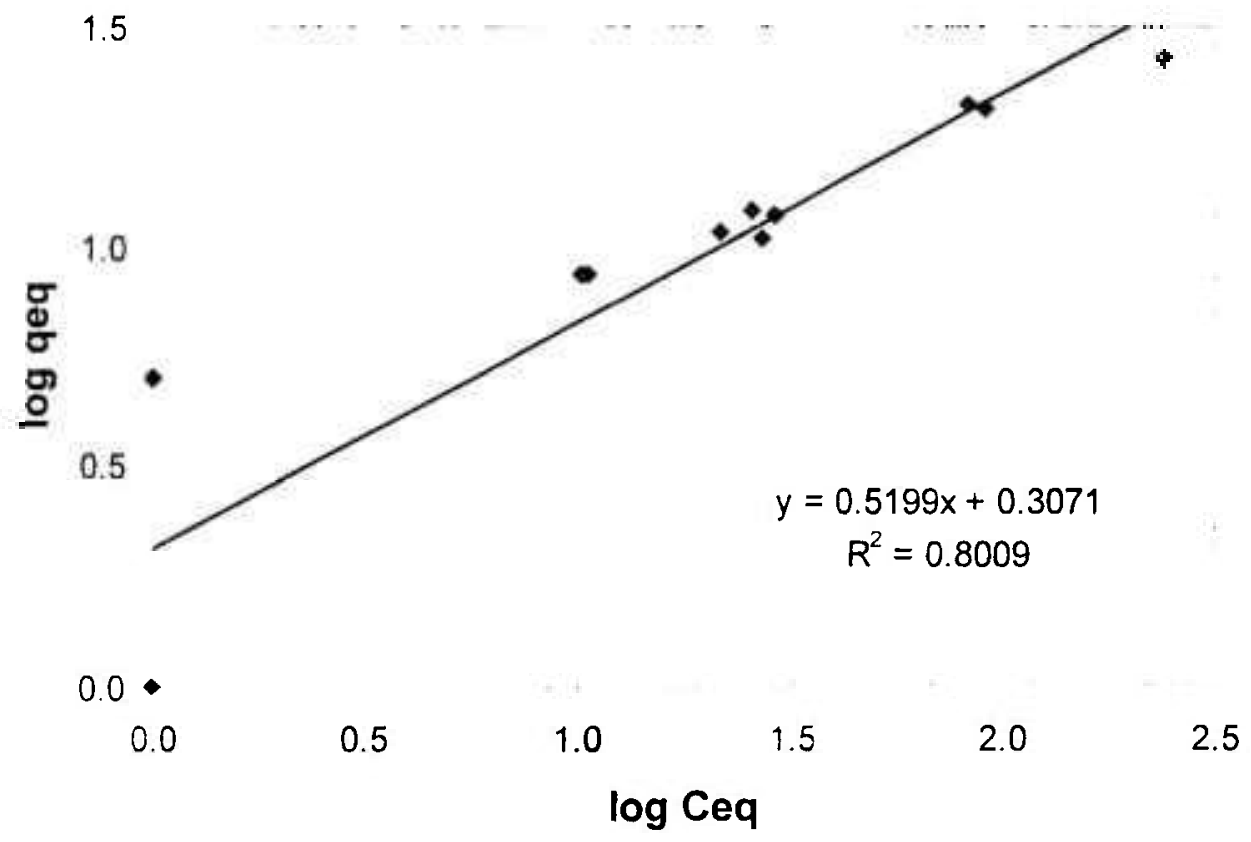

FIGURA 26 - Isoterma linearizada de Freundlich para $\mathrm{UO}_{2}{ }^{2+}$ de soluções nitricas em pH 5 para a magnetita lavada com água. a $27^{\circ} \mathrm{C}$. 
Os valores da capacidade, da constante de Langmuir $\left(\mathrm{K}_{\mathrm{L}}\right)$, da intensidade de adsorção $(1 / n)$ e da constante de Freundlich $\left(K_{F}\right)$, foram determinados conforme descritos no item 3.4.4, para as equações neste caso, $y$ $=0,0353 x+0,8774$ da isoterma de Langmuir e $y=0.5199 x+0,3071$ da isoterma de Freundlich.

Conforme observa-se na TAB.3, tem-se que:

A capacidade máxima de adsorção é de $28 \pm 1 \mathrm{mg} \cdot \mathrm{g}^{-1}$, ou seja para cada grama de magnetita tem-se uma remoção de $28 \pm 1 \mathrm{mg} \mathrm{de} \mathrm{UO}_{2}{ }^{2+}$. O valor de $1 / n$ é menor do que uma unidade indicando que o processo de adsorção do $\mathrm{UO}_{2}{ }^{2+}$ pela magnetita é favorável.

O modelo que melhor se aplicou ao processo de adsorção, segundo a forma linearizada, é o de Langmuir, pois apresentou maior concordância com os dados experimentais, verificado pelo alto valor de coeficiente de correlação linear $\left(r^{2}\right)$, indicando também, que o fenômeno ocorreu com formação de monocamada sobre a superfície do adsorvedor.

TABELA 3 - Parâmetros de Langmuir e Freundlich para Adsorção de ĺons de Urânio de Meio Nitrico, pH 5, dose $15 \mathrm{~g} \cdot \mathrm{L}^{-1}$, a $27^{\circ} \mathrm{C}$, para a Magnetita (com água).

\begin{tabular}{lccccc}
\hline & $r^{2}$ & $\mathrm{~K}_{\mathrm{L}}$ & $\mathrm{Q}\left(\mathrm{mg} \cdot \mathrm{g}^{-1}\right)$ & $\mathrm{K}_{\mathrm{F}}$ & $1 / \mathrm{n}$ \\
\hline Langmuir & 0,9455 & 0,0402 & $28 \pm 1$ & - & - \\
Freundlich & 0,8009 & - & - & 2,03 & 0,5199 \\
\hline
\end{tabular}

A FIG. 27 mostra as isotermas de adsorção de Langmuir e Freundlich, confirmando que o melhor modelo é o de Langmuir. 


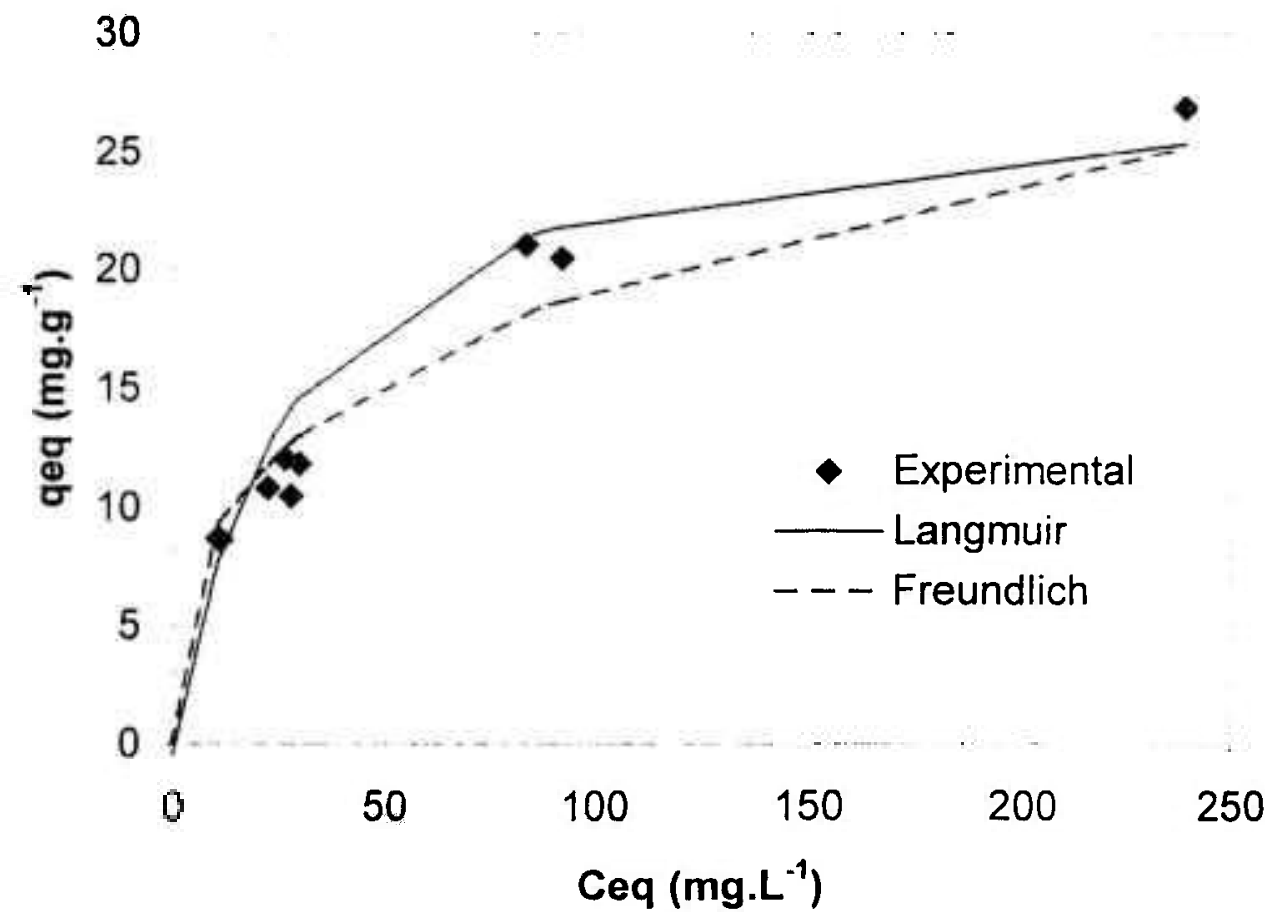

FIGURA 27 - Isotermas de Adsorção de Langmuir e Freundlich para $\mathrm{UO}_{2}{ }^{2+}$ de Soluções Nitricas para a Magnetita Lavada com Água, em pH 5 , a $27^{\circ} \mathrm{C}$.

\subsection{Energia Livre de Gibbs}

Utilizando-se os valores de $K_{L}$ obtidos nas TAB.2 e 3, com a equação demonstrada no item 3.4 .5 e TAB.1, é possivel calcular a energia livre de Gibbs, $\Delta G^{\circ}$ ads e determinar se o processo de adsorção é físico ou químico.

Para a magnetita lavada com metanol, o valor $\lrcorner G^{\circ}$ ads encontrado foi de $-22,5 \pm 0,1 \mathrm{~kJ}$. mol ${ }^{-1}$ e para a magnetita lavada com água, 0 valor $\Delta G^{\circ}$ ads encontrado foi de $-23,2 \pm 0,1 \mathrm{~kJ}$. $\mathrm{mol}^{-1}$.

Os valores de $\lrcorner \mathrm{G}^{\circ}$ ads indicaram que para ambos os casos ocorreu processo de adsorção química e espontânea [16], à temperatura de trabalho de $27^{\circ} \mathrm{C}$. 


\section{CONCLUSÕES}

$\mathrm{O}$ estudo de nanoparticulas de magnetita $\left(\mathrm{Fe}_{3} \mathrm{O}_{4}\right)$, para remoção de ions $\mathrm{UO}_{2}{ }^{2+}$ em meio nitrico, demonstrou que a magnetita é um material adsorvedor eficiente e de baixo custo que pode ser utilizado no tratamento de rejeitos liquidos radioativos provenientes do ciclo do combustivel nuclear.

Pelos estudos de caracterização, observou-se pelo espectro de raios- $X$ que se trata de um material formado predominantemente pela magnetita, com forte magnetização e sem apresentar o comportamento de histerese, caracteristica atribuida às propriedades superparamagnéticas das nanopartículas de magnetita, com tamanhos menores que $26 \mathrm{~nm}$. Foi possível perceber no MEV que particulas menores de magnetitas estão incrustadas em particulas maiores.

Verificou-se que o processo de adsorção de $\mathrm{UO}_{2}{ }^{2+}$ é influenciado pelo $\mathrm{pH}$ da solução em que os mesmos estão contidos. As máximas remoções obtidas neste estudo ocorreram em pH 4 e pH 5. Em pH 2 e pH 10, percebeu-se um decréscimo acentuado na \% de remoção, ocasionado pela dissolução da magnetita, devido a alta acidez e à formação de espécies de hidroxi-uranilo negativamente carregado e de baixa adsortividade, respectivamente. Posteriormente os estudos indicaram que a solução com pH 5 apresentou melhor resultado.

No estudo de dose, constatou-se que a capacidade de adsorção da magnetita em pH 5 diminui exponencialmente com o aumento da dose de magnetita e com tendência a se tornar constante em doses acima de $40 \mathrm{~g} \cdot \mathrm{L}^{-1}$. Já, a porcentagem de remoção atinge um máximo muito próximo de $100 \%$ em doses a partir de $30 \mathrm{~g} \cdot \mathrm{L}^{-1}$. 
A cinética de adsorção também foi considerada como fator importante no comportamento desse sistema, tendo como melhores tempo e velocidade de agitação, 40 minutos e $300 \mathrm{rpm}$, respectivamente, onde se encontraram as melhores \% de remoção. A partir destes, os valores mostraram-se constantes.

Com as melhores condições de adsorção estabelecidas obtiveram-se as isotermas, à temperatura ambiente, variando a concentração de $U$ para a magnetita lavada com metanol e para a magnetita lavada somente com água.

O modelo de isoterma que melhor se aplicou aos dados experimentais de adsorção de $\mathrm{UO}_{2}{ }^{2+}$, foi de Langmuir, para ambos os casos, sugerindo que 0 processo de adsorção ocorrido foi o mesmo para as duas magnetitas.

As capacidades máximas de adsorção encontradas foram $27 \pm 1 \mathrm{mg} \cdot \mathrm{g}^{-1}$ e $28 \pm 1 \mathrm{mg}^{-1}$ para as magnetitas lavadas com metanol e água, respectivamente.

Tendo em vista os valores de capacidades máximas de adsorçōes muito próximos verificou-se que a grande vantagem da magnetita lavada com metanol foi o tempo de secagem muito menor em relação ao tempo de secagem necessária para a magnetita lavada com água.

Por meio de estudos termodinâmicos determinou-se a energia livre de Gibbs, a qual descreveu o processo de adsorção química e espontânea para remoção de $\mathrm{UO}_{2}{ }^{2+}$ pela magnetita.

Dos estudos realizados, conclui-se então, que a magnetita é um adsorvente promissor com possibilidade de aplicação da tecnologia de separação magnética combinada com a separação química em processos de tratamento de rejeito líquido nuclear. A magnetita obtida é superparamagnética e mostrou-se eficiente na adsorção de $\mathrm{UO}_{2}{ }^{2+}$, além de ser facilmente obtida em laboratório por precipitação simultânea de ions $\mathrm{Fe}^{2+}$ e $\mathrm{Fe}^{3+}$ bem como pode ser obtida de residuos siderúrgicos de baixo custo. 
O uso de magnetita superparamagnética possibilita a aplicação da técnica de separação magnética [79], reduzindo os custos operacionais visto que dispensa as etapas de centrifugação e ou filtração utilizadas na separação liquido-sólido. Após a adsorção de $\mathrm{UO}_{2}{ }^{2+}$, a magnetita pode ser facilmente removida do meio líquido por aplicação de um campo magnético. $O$ rejeito de urânio adsorvido na magnetita é um rejeito sólido, de armazenamento fáci seguro que a forma liquida.

$\dot{E}$ importante salientar, que para usar a magnetita em um rejeito radioativo real, são necessárias mais investigações que mostrem a influência de outros ions ou de complexantes de diferentes efluentes radioativos, que serão objetivos de estudos futuros. 


\section{REFERÊNCIAS BIBLIOGRẢFICAS}

[1] KADIRVELU, K.; KAVIPRIYA, M.; KARTRIKA, C.; RADHIKA, M.; VENNILAMANI, N.; PATTABHI, S. Utilization of various agricultural wastes for activated carbon preparation and application for the removal of $c / e s$ and metal ions from aqueous solutions. Bioresour. Technol., v. 87, p. 29-132, 2003.

[2] SAEED, A.: AKHTER, M.W.; IQBAL, M. Removal and recovery of heavy metals from aqueous solution using papaya wood as a new biosorbent. Sep. Purif. Technol., v.45, p. 25-31, 2005.

[3] GUPTA, V.K.; ALI, I. Removal of lead and chromium from wastewater using bagasse fly ash-a sugar industry waste. J. Colloid Interface Sci., v.271, p. 321-328. 2004.

[4] KUMAR, U.; BANDYOPADHYAY, M. Fixed bed column study for Cd (II) removal from wastewater using treated rice husk. J. Hazard. Mater. , v. B 129, p. 253-259, 2006.

[5] RODRIGUES, K. C. Caracterização cristalina e magnética de precipitados de magnetita obtidos na preparação do ferrofluido Fesub30sub4+Dsub20. 1994. Dissertação (mestrado) - Instituto de Pesquisas Tecnológicas - IPEN, São Paulo, p. 1-40.

[6] ORTIZ, N.: SUSCA, C; OLIVEIRA, K.M.R.; BRESSIANI, J.C. Estudo da estabilidade química da magnetita como adsorvedor na remoção de compostos orgânicos de soluções. Cerâmica, v. 49, n. 312, p. 216-222, 2003.

[7] INTERNATIONAL ATOMIC ENERGY AGENCY. Handling and Processing of Radioactive Waste from Nuclear Applications. Vienna: IAEA, 2001 (Technical Reports Series, 402).

[8] KRUEGER, S.; OLSON, G.J.; RHYNE, J.J.; BLAKEMORE, R.P.; GORBY, $Y$.A.; BLAKEMORE, N. Small Angle neutron and X-ray scattering from magnetite crystals in magnetotactic bacteria. J. Magn. Magn. Mater., v. 82, p. 17-28, 1989.

[9] ROSIĖRE.C.A.; RENGER ,F.E.; PIUZANA,D.; SPIER,C.A. Marco estrutural, histórico e geográfico do Quadrilátero Ferrifero. In: WINGE,M.; SCHOBBENHAUS,C.; BERBERT-BORN,M.; QUEIROZ,E.T.; CAMPOS,D.A.; SOUZA.C.R.G. ; FERNANDES,A.C.S. (Edit.) Sítios Geológicos e Paleontológicos do Brasil. 2005. Disponivel em: <http://www. unb.br/ig/sigep/sitio042/sitio042.pdf>. Acesso em: 10 fev. 2006. 
[10] SCHWERTMANN, U. ; CORNELL, R.M. Iron Oxides in the Laboratory: Preparation and Characterization. New York. N.Y.: VCH publishers, Inc., 1991.

[11] SCOTT, T. B.; ALLEN, G. C.; HEARD, P. J.; RANDELL, M. G. Reduction of $\mathrm{U}(\mathrm{VI})$ to $\mathrm{U}(\mathrm{IV})$ on the surface of magnetite. Geochim. Cosmochim. Acta, v. 69, n. 24, p. 5639-5646, 2005.

[12] COTTON, F.A.; WILKINSON, G. Advanced Inorganic Chemistry. New York, N.Y.: John Wiley \& Sons, Inc., Wiley-Interscience Publication, 1972.

[13] BOYD, T.E.; KOCHEN, R.L.; RIORDAN,G.A.; MORALES, L.M. Ferrite Treatment of Actinide Waste Solutions: A Preliminary Study. Chemical Separations Processes for Plutonium and Uranium, CO, Rockwell International, July 30, 1982. (RFP-3299).

[14] BOYD, T.E.; KOCHEN, R.L.; PRICE, M.Y. Removal of Radioactive Materials from Waste Solutions Via Magnetics Ferrite. In: AMERICAN NUCLEAR SOCIETY TROPICAL MEETING ON TREATMENT AND HANDLING OF RADIOACTIVE WASTE. April 19-22, 1982, Richland, WA,. Proceedings... Richland, WA, 1982.

[15] TODOROVIC, M.; MILONJIC, S.K.; COMOR, J.J; GAL, I.J. Adsorption of Radioactive lons ${ }^{137} \mathrm{Cs}^{+},{ }^{85} \mathrm{Sr}^{2+}$, and ${ }^{60} \mathrm{Co}^{2+}$ on Natural Magnetite and Hematite. Sep. Sci. Technol. v. 27, N. 5, p. 671-679. 1992.

[16] ORTIZ, N., Estudo de utilização da magnetita como material adsorvedor dos metais $\mathrm{Cu}^{2+}, \mathrm{Pb}^{2+}, \mathrm{Ni}^{2+}$ e $\mathrm{Cd}^{2+}$, em solução. 2000. Tese (doutorado) Instituto de Pesquisas Tecnológicas - IPEN, São Paulo, p. 1-56 e p. 66-105.

[17] MACHADO, F.B.; MOREIRA, C.A.; ZANARDO, A.; ANDRÉ, A.C.; GODOY, A.M.; FERREIRA, J.A.; GALEMBECK, T.; NARDY, A.J.R.; ARTUR, A.C.; OLIVEIRA, M.A.F. Enciclopédia Multimídia de Minerais e Atlas de Rochas. Disponivel em: <http://www.rc.unesp.br/museudpm>. Acesso em: 10 jan. 2006.

[18] BOYD, T.E.; CUSICK, M.J.; NAVRATIL, J.D. Ferrite separation science and technology. In: N.N. LI AND J.D. NAVRATIL (eds). Recent Developments in Separation Science. Boca Raton, FL: CRC Press, Inc., v. 8, p. 207-232, 1986.

[19] YAMAURA, M.; CAMILO, R.L.; COHEN, V.H.; GONÇALVES, M.A. Remoção de $\mathrm{Cr}(\mathrm{VI})$ para o tratamento de efluentes industriais utilizando a magnetita. In: $V$ ENCONTRO NACIONAL DE APLICAÇÕES NUCLEARES (ENAN), 1520 out., 2000, Rio de Janeiro, Brasil. Anais..., 2000. 
[20] YAMAURA, M.; PERIN,T.R. Remoção de európio por precipitação da ferrita. In: INTERNATIONAL NUCLEAR ATLANTIC CONFERENCE (INAC) / VI NATIONAL MEETING ON NUCLEAR APPLICATIONS (ENAC), 11-16 ago., 2002, Rio de Janeiro, Brasil. Anais..., 2002. CD-ROM, 4 p.

[21] NAVRATIL, J.D. Trace metal recovery and concentration using ferrites. J. Radioanal. Nucl. Chem., v. 183 (1), p.135-138, 1994.

[22] GONÇALVES, M.A.; YAMAURA, M.; MINDRICZ, A. Z.; LANDGRAF, F.J.G. Influence of Magnetic field properties on the metals adsorption capacity of synthetic magnetite in aqueous effluents treatment. In: ACS NATIONAL MEETING. August 23-27, 1998, Boston, Massachusetts, USA, 1998. Proceedings... Boston, Massachusetts, 1998.

[23] HU, Q.; CHEN, F.; LI, B.; SHEN, J. Preparation of three-dimensional nanomagnetite/chitosan rod. Mat. Lett., v. 60, p. 368-370, 2006.

[24] MORNET , S.; VASSEUR , S.; GRASSET , F.; VEVERKA , P.; GOGLIO, G.; DEMOURGUES , A.; PORTIER , J.; POLLERT, E.; DUGUET , E. Magnetic nanoparticle design for medical applications. Prog. Solid State Chem. 2006. No prelo.

[25] GRAINGER, L. Uranium and Thorium, London: George Newness Limited, 1958.

[26] LAMARSH, J. R; BARATTA, A.J. Introduction to Nuclear Engineering, New Jersey, Prentice Hall, p. 209, 2001.

[27] KALTISOYANNIS, N.; SCOTT, P. The f elements, Oxford Chemistry Primers. New York, N.Y.: Oxford University Press, Inc., 1999.

[28] INTERNATIONAL ATOMIC ENERGY AGENCY. Significance of Mineralogy in the Development of Flow sheets for Processing Uranium Ores. Vienna, IAEA, 1980 (Technical Reports Series, 196).

[29] INDÚSTRIAS NUCLEARES DO BRASIL - INB. Ministério da Ciência e Tecnologia. Urânio no Brasil. Disponivel em: <http://www.inb.gov.br>. Acesso em: 20 jan. 2006.

[30] LEWIS, E.E. Nuclear Power Reactor Safety. New York: John Wiley \& Sons, Inc., 1977.

[31] INTERNATIONAL ATOMIC ENERGY AGENCY. Regulations for the safe transport of radioactive materials. 1985 Edition (As Amended 1990), Vienna, 1990 (Safety Series, 6). 
[32] INTERNATIONAL ATOMIC ENERGY AGENCY. Methods for the Minimization of Radioactive Waste from Decontamination and Decommissioning of Nuclear Facilities. Vienna, IAEA, 2001 (Technical Reports Series, 401).

[33] MORALES, R.K.; ALVES. R.N.; SAAD, S. Impacto radiológico global dos fertilizantes fosfatados. In: VI CONGRESSO GERAL DE ENERGIA NUCLEAR (CGEN). 27 out. - 01 nov., 1996. Rio de Janeiro. Brasil. Anais..., 1996.

[34] FERNANDES, H.M. Radioatividade Natural. Tecnologia humana aumenta risco de exposição. Ciência Hoje, v. 28 (166), p. 36-42, 2000.

[35] CULLITY, B.D. Introduction to magnetic materials. New York, N.Y.: Addison-Wesley Publishing Company, p. 181-190, 1972.

[36] SCHAKE, A.R.; AVENS, L.R.; PADILLA, D.D.; ROMERO, L.A.; WORL, D.A. Magnetic separation for environmental remediation. In: K.L. Nash and G.R. Choppin (eds). Separation of elements. New York, N.Y. Plenum Press, p. 257-269, 1995.

[37] CHOI, S.K. A study on the elimination of heavy metals from sewage by precipitation using artificially prepared magnetite. $\mathrm{Ph}$. $\mathrm{D}$. Thesis, Technical University of Hamburg-Harburg, 1993.

[38] SLATER, S.A.; CHAMBERLAIN, D.B.; AASE, S.A.; BABCOCK, B.D.; CONNER, C.; SEDLET, J.: VANDERGRIFT, G.F. Optimization of magnetite carrier precipitation process for plutonium waste reduction. Sep. Sci. Technol., v.32, n. 1-4, p. 127-147, 1997.

[39] KOCHEN, R.L.; NAVRATIL. J.D. Removal of radioactive materials and heavy metals from water using magnetic resin. U.S. Patent 5.595.666, Jan. 21, 1997.

[40] TSOURIS, C.; YIACOUMI. S. Particle flocculation and filtration by highgradient magnetic fields. Separ. Sci. Technol. v. 32, n. 1-4, p. 599-616, 1997.

[41] WILLIAMS, J. A.; BAXTER. W.; COLLINS, G.; HARDING, K.: LESLIE, C.M.; SILLS, R.J. The application of high gradient magnetic separation in nuclear fuel reprocessing. Nucl. Technol., v. 52, p.284-294, 1981.

[42] LADEIRA, A.C.Q.; MORAIS. C.A. Uranium recovery from industrial effluent by ion exchange-coumn experiments. Min. Eng. 18, p. 1337-1340, 2005. 
[43] YAMAURA, M.; MATSUDA, H.T. Sequential separation of actinides and lanthanides by extraction chromatography using a CMPO-TBP/XAD7 column. J. Radioanal. Nucl. Chem., v. 241 (2), p. 277-280, 1999.

[44] INTERNATIONAL ATOMIC ENERGY AGENCY. Chemical precipitation processes for the treatment of aqueous radioactive wastes. Vienna, 1992 (Technical Report Series n. 337)

[45] NOBRE, J.S.M. Separação e concentração de urânio por cromatografia de extração - sistema U(VI) $-\mathrm{H}_{3} P \mathrm{O}_{4}$. 1981. Dissertação (mestrado) INSTITUTO DE PESQUISAS ENERGÉTICAS E NUCLEARES (IPEN), São Paulo.

[46] KIITAHYALI, C.; ERAL, M. Selective adsorption of uranium from aqueous solutions using actived carbon prepared from charcoal by chemical activation. Sep. Purif. Technol., v. 40, p. 109-114, 2004.

[47] WEI, Y-Z. ; YAMAGUCHI, M.; KUMAGAI, M.; TAKASHIMA, Y.; HOSHIKAWA, T.; KAWAMURA, F. Separation of actinides from simulated spent fuel solutions by na advanced ion-exchange process. J. Alloys Compd., v. 271-273, p. 693-696, 1998.

[48] YAMAURA, M. Partição de actinideos e de produtos de fissão de rejeito líquido de alta atividade. 1999. Tese (doutorado) - INSTITUTO DE PESQUISAS ENERGÉTICAS E NUCLEARES (IPEN), São Paulo.

[49] MCKAY, H.A.C.; MILES, J.H.; SAWANSOM, J.L. The Purex Process. In: SCHULZ, W.W.; BURGER, H.L.; NAVRATIL, J.D., Science and technology of tributyl phosphate. V. III - Application of tributyl phosphate in nuclear fuel reprocessing. CRC Press, Inc., Boca Raton, FL. V.3, P. 1-9, 1990.

[50] CERUTTI, E.L. Separação de compostos petroquímicos em unidades de leito móvel simulado. 2003. Dissertação (mestrado) - UNIVERSIDADE FEDERAL DE SANTA CATARINA , p. 1-10.

[51] MELLAH, A.; CHEGROUCHE, S.; BARKAT, M. The removal of uranium (VI) from aqueous solutions onto activated carbon: Kinetic and thermodynamic investigations. J. Colloid Interface Sci. 2006. No prelo.

[52] PARAB, H.; JOSHI, S.; SHENOY,N.; VERMA, R.; LALI, A.; SUNDERSANAN, $M$. Uranium removal from aqueous solution by coir pith: equilibrium and kinetic studies. Bioresour. Technol. v. 96, n. 11, p. 1241-1248, 2005.

[53] CATALANO, J.G.; BROWN JR, G.E. Uranyl adsorption onto montmorillonite: Evaluation of binding sites and carbonate complexation. Geochim. Cosmochim. Acta. v. 69, n. 12, p. 2295-3005, 2005. 
[54] YAMAMURA, A.P.G; YAMAURA, M. Estudo da cinética e das isotermas de adsorção de $U$ pelo bagaço de cana-de-açúcar. In: INTERNATIONAL NUCLEAR ATLANTIC CONFERENCE (INAC) / VII NATIONAL MEETING ON NUCLEAR APPLICATIONS (ENAC), 28 ago. - 02 set., Santos. Brasil, 2005. Anais..., 2005.

[55] BONIOLO, M.R.; YAMAURA, M. Viabilidade do uso da casca de banana como adsorvente de ions de urânio. In: INTERNATIONAL NUCLEAR ATLANTIC CONFERENCE (INAC) / VII NATIONAL MEETING ON NUCLEAR APPLICATIONS (ENAC), 28 ago. - 02 set., Santos, Brasil, 2005. Anais..., 2005.

[56] KAPLAN, D.I.; SERKIZ, S.M. Quantification of thorium and uranium sorption to contaminated sediments. J. Radioanal. Nucl. Chem. V.248, p.529, 2001.

[57] BARANIAK, L.; BERNHARD, G.; NITSCHE, H. Influence of hydrothermal wood degradation products on the uranium adsorption onto metamorphic rocks and sediments. J. Radioanal. Nucl. Chem. v. 253, p.185, 2002.

[58] CHOI, S.; CALMANO, W.; FORSTNER, U. Studies for separation of heavymetals from wastewater with freshly precipitated magnetite. Acta Hydro et Hydro (22), v. 6, p. 254-260, 1994. In: ORTIZ, N., Estudo de utilização da magnetita como material adsorvedor dos metais $\mathrm{Cu}^{2+}, \mathrm{Pb}^{2+}, \mathrm{Ni}^{2+}$ e $\mathrm{Cd}^{2+}$, em solução. 2000. Tese (doutorado) - Instituto de Pesquisas Tecnológicas IPEN, São Paulo, p. 1-56 e p. 66-105.

[59] MISSANA, T.; GARCIA-GUTIÉRREZ, M.; MAFFIOTTE, C. Experimental and modeling study of the uranium (VI) sorption on goethite. J. Colloid Interface Sci. v. 260, p. 291-301, 2003.

[60] WAITE, T.D.; DAVIS, J.A.; PAYNE, T.E.; WAYCHUNAS, G.A.; XU. N. Uranium (VI) adsorption to ferrihydrite: Application of a surface complexation model. Geochim. Cosmochim. Acta. v. 58, p. 5465-5478, 1994.

[61] EL-AAMRANI, F.; CASAS L.; DE PABLO, J.; DURO, L.; GRIVÉ, M.; BRUNO, $J$. Experimental and modeling study of the interaction between $U(V I)$ and magnetite. J. Conf. Abstr. v. 5, p. 2-378, 2000.

[62] SAGERT, N.H.; HO C.H.; MILLER, N.H. The adsorption of U(VI) onto a magnetite solution. J. Colloid Interface Sci. v. 130, n.1, p. 283-287. 1989.

[63] VENKATARAMANI, B.; GUPTA. A.R. Effect of anions on the sorption of uranyl ions on hydrous oxides: Application of the surface hydrolysis model.

Colloids Surf. , v. 53, p. 1-19, 1991. 
[64] MISSANA, T.; GUTIÉRREZ, M.G.; FERNANDEZ, V. Uranium (VI) sorption on colloidal magnetite under anoxic environment. Experimental study and surface complexation modeling. Geochim. Cosmochim. Acta. v. 67, p. 2543-2550, 2003.

[65] DZOMBAK, D.A.; MOREL, F.M. Surface Complexation Modelling. New York, N.Y.: John Wiley. p. 393, 1990.

[66] FAUST, S.D.; ALY, O.M., Adsorption processes for water treatment. Boston, MA: Butterworths, 1987.

[67] SINGH, K.P.; MOHAN, D; TANDON, G.S.; GUPTA, G.S.D. Vapor-Phase Adsorption of Hexane and Benzene on Activated Carbon Fabric Cloth: quilibrium and Rate Studies. Ind. Eng. Chem. Res. v. 41, p. 2480-2486, 2002.

[68] YU. L. Some consideration on the Langmuir isotherm equation. Colloids Surf., A. v. 274, p. 33-36, 2006.

[69] CULLITY, B.D. Elements of X-ray diffraction. New York, N.Y: AddisonWesley Publishing Company, 1959.

[70] KLUG, H.P.; ALEXANDER, L.E. X-ray diffraction procedures for polycrystalline and amorphous materials. New York, N.Y.: John Wiley \& Sons, Inc., $2^{\text {nd }}$ Edition, 1974.

[71] CASTRO. A. R. M., Textura cristalográfica e avaliação de domínios magnéticos em imãs de PrFeB. 2001. Tese (doutorado) - Instituto de Pesquisas Energéticas e Nucleares - IPEN, São Paulo, p. 38-47.

[72] PANKHURST, Q.A.; CONNOLLY, J.; JONES, S.K.; DOBSON, J. Applications of magnetic nanoparticles in biomedicine. J. Phys. D: Appl. Phys. v. 36, p. R167-R181, 2003.

[73] MALISKA, A.M. Microscopia eletrônica de varredura e Microanálise, Universidade Federal de Santa Catarina - UFSC, Departamento de Engenharia Mecânica. Disponivel em:

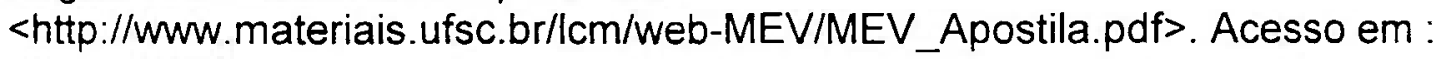
25 jan. 2006.

[74] DUARTE, L.C.; JUCHEM, P.L.; PULZ. G.M.; BRUM, T.M.M.; CHODUR, N.: LICCARDO, A.; FISCHER, A.C.; ACAUN, R.B. Aplicações de Microscopia Eletrônica de Varredura (MEV) e Sistema de Energia Dispersiva (EDS) no Estudo de Gemas: exemplos brasileiros. Universidade Federal do Rio Grande do Sul - Instituto de Geociências. Pesquisas em Geociências. v. 30. n. 2, p. 3-15, 2003. 
[75] JEFFERY. G.H.; BASSET, J.; MENDHAM, J.: DENNEY, R.C. VOGEL -

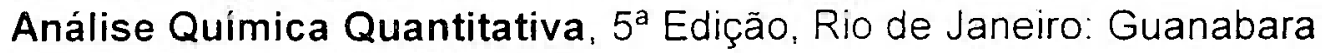
Koogan S.A., p. 522-588, 1992.

[76] YAMAURA, M.; WADA, L.Y.; RIBEIRO, F.C. Determinação espectrofotométrica de urânio( $\mathrm{VI})$ com arsenazo III, em meio nítrico. Rev. Bras. Pesq. Des. v. 4, n. 3, p. 1024-1028, 2002.

[77] YAMAURA, M.; CAMILO, R.L.; SAMPAIO, L.C.; MACÊDO, M.A.; NAKAMURA, M.; TOMA, H.E. Preparation and characterization of (3aminopropyl)triethoxysilane-coated magnetite nanoparticles. J. Magn. Magn. Mater. v. 279, n. 2-3, p. 210-217, 2004.

[78] MISSANA, T.; MAFFIOTTE, C.; GUTIÉRREZ, M. G. Surface reactions kinetics between nanocrystalline magnetite and uranyl. J. Colloid Interface Sci. v. 261, p. 154-160, 2003.

[79] YAMAURA, M.; CAMILO, R.L.; MOURA, E. Preparação de nanopartículas magnéticas silanizadas para utilização em técnicas de separação magnética. In: INTERNATIONAL NUCLEAR ATLANTIC CONFERENCE (INAC) / VI NATIONAL MEETING ON NUCLEAR APPLICATIONS (ENAC), 11-16 ago., 2002, Rio de Janeiro, Brasil. Anais..., 2002. CD-ROM, 4 p. 